\title{
Analysis of the Changes in the Water Yield Coefficient over the Past 50 Years in the Huang-Huai-Hai River Basin, China
}

\author{
Xiaoqing Shi $\mathbb{D}$,, Tianling Qin $\left(\mathbb{D},{ }^{1}\right.$ Denghua Yan $\mathbb{D}^{\mathbb{D}},{ }^{1}$ Ruochen Sun ${ }^{1}{ }^{2},{ }^{2}$ Shuang Cao $\mathbb{D},{ }^{3}$ \\ Lanshu Jing $\oplus^{1},{ }^{4}$ Yang Wang ${ }^{10},{ }^{1}$ and Boya Gong $\oplus^{1}$ \\ ${ }^{1}$ State Key Laboratory of Simulation and Regulation of Water Cycle in River Basin, China Institute of Water Resources and \\ Hydropower Research, Beijing 100038, China \\ ${ }^{2}$ College of Water Conservancy and Environment, Zhengzhou University, Zhengzhou, Henan Province 450001, China \\ ${ }^{3}$ College of Architecture and Engineering, Beijing University of Technology, Beijing 100124, China \\ ${ }^{4}$ College of Water Conservancy and Hydropower, Hebei University of Engineering, Hebei 056038, China
}

Correspondence should be addressed to Tianling Qin; qintl@iwhr.com

Received 19 July 2017; Revised 19 November 2017; Accepted 2 December 2017; Published 15 May 2018

Academic Editor: Stefania Bonafoni

Copyright (C) 2018 Xiaoqing Shi et al. This is an open access article distributed under the Creative Commons Attribution License, which permits unrestricted use, distribution, and reproduction in any medium, provided the original work is properly cited.

\begin{abstract}
This study analysed the temporal and spatial changes in the water yield coefficient (WYC), which represents the ratio of the gross amount of water resources to precipitation. Factors such as precipitation, rainstorm days, rainless days, vegetation cover change, and land use/cover change were considered to determine the causes of these changes. The results led to the following conclusions: (1) The average annual WYC of the Huang-Huai-Hai River Basin is between 0.03 and 0.58 , with an average value of 0.17 , which is smaller than the national average WYC of 0.4. (2) Temporally, the WYC varied slightly, with the western part showing a negative trend and the eastern part showing a positive trend. The WYC is positively correlated with precipitation, rainstorm days, and the normalized difference vegetation index (NDVI) and negatively correlated with rainless days. However, a slower change in NDVI produced a faster change in WYC. In areas with land use types exhibiting a large evapotranspiration decrease, the rate of change in the WYC increased. (3) Spatially, the distribution is fairly regular, exhibiting a gradual increase from the northern part of the Yellow River Basin (WYC < 0.1) to the surrounding areas. When the WYC is correlated with precipitation, rainstorm days, rainless days, and NDVI, the $R^{2}$ values of the linear fitting results are $0.98,0.91,0.96$, and 0.73 , respectively. The WYC is positively correlated with precipitation, rainstorm days, and vegetation coverage and negatively correlated with rainless days, but the correlation coefficient is greatly influenced by the precipitation characteristics and land use types. In areas featuring high proportions of land use types associated with high evapotranspiration, the average WYC is low.
\end{abstract}

\section{Introduction}

The water yield coefficient (WYC) refers to the proportion of the amount of gross water resources (i.e., the amount of surface water and groundwater that does not overlap with surface water generated by precipitation) in a region. This parameter reflects the potential of precipitation to transform into water resources and a region's water yielding capacity. According to the definition, changes in the WYC are mainly related to changes in the precipitation characteristics and/or the underlying surface conditions [1-6].

In recent years, under the influence of global climate change and human activities, the water cycle has changed dramatically. The spatial and temporal distribution of water resources has become uneven, and extreme precipitation events and droughts are occurring more frequently. Meanwhile, the underlying surface condition changes have led to changes in the process of runoff yield and convergence, resulting in considerable challenges for sustainable water resource utilization and development [7-10]. One such area is the Huang-Huai-Hai River Basin, which refers to three subriver basins, namely, the Yellow River Basin, the Huai River Basin, and the Hai River Basin. It occupies an important position in the national water resources strategic layout. However, for a long time, the region has had a high frequency of drought and flood disasters and surface water resource 
shortages, coupled with areas of overexploitation of the groundwater; hence, the water resource decay problem is serious $[11,12]$.

Recently, many scholars have studied the precipitation change and related problems in the Huang-Huai-Hai River Basin. Zhang et al. [13] used twelve indicators to analyse the temporal and spatial changes in extreme precipitation in the Huang-Huai-Hai River Basin. Yan et al. [14] focused on whether the change in precipitation intensity after a drought event in the Huang-Huai-Hai River Basin was larger than before. Yin et al. [15] explored the occurrence of extreme precipitation events in the Huang-Huai-Hai River Basin from 1961 to 2011 and then simulated and predicted the possible future situation. Yang et al. [16] used the $Z$ index of precipitation to evaluate the drought and flood conditions in the Huang-Huai-Hai River Basin and explored the temporal and spatial distributions of drought and flood events and their combined characteristics. Yuan et al. [17] studied the spatiotemporal variability of the two special extreme events-consecutive drought and heavy rain after a drought.

Precipitation is the main source of regional water resources, and, in general, a change in precipitation results in a change in the regional gross water resources amount. Hao et al. [18] found that the gross water resources amount was positively correlated with the annual precipitation in a study on the impact of climate change on the gross water resources amount in Hebei Province with a correlation coefficient of 0.913 and a confidence level that was greater than 0.001. Sun et al. [19] proposed a consistency test method based on a hydrological statistical theory that replaces the precipitation-water yield line with the WYC in a study of future water resource forecasting methods in water-deficient areas. Then, they analysed and predicted the trend of the gross water resources amount in northwestern Liaoning Province. However, Gao and Huang [20] analysed the annual WYC and annual precipitation of provinces and cities in China and found good positive correlations in most provinces (as well as cities and districts): high annual precipitation is associated with a large WYC, and low precipitation is associated with a small WYC. They also observed a negative correlation or no obvious relationship between the annual WYC and the annual precipitation in some provinces (as well as cities and districts); however, the WYC is relatively stable. Thus, in this case, consideration should be given to other underlying factors other than precipitation, such as vegetation, and land use/cover (LUC).

Many scholars have also studied the effects of underlying conditions, such as vegetation and LUC, on the hydrological cycle. Based on the study of the impact of global land use/cover change (LUCC) on the terrestrial water cycle, scholars have argued that human activities have altered the LUC, thereby affecting $\mathrm{CO}_{2}$ emissions, the vegetation, and the evapotranspiration (ET) and runoff [21, 22]. Mishra et al. [23] examined the relative effects of regional LUC patterns and future climate change projections on hydrological processes and found that certain LUCC types (converting forests to farmland) result in reduced ET and increased flow. Twine et al. [24] also concluded that when grassland is converted into cropland, the amount of ET will increase. Liu et al. [25] used an integrated dynamic land ecosystem model (DLEM) and spatial LUCC data to estimate the effect of LUCC on the magnitude and spatiotemporal pattern of variations in ET, runoff, and water yield in China. The results showed that urban sprawl and forest-grassland conversion decreased ET and increased the water yield. Most deforested areas converted into paddy land or irrigated dry farmland normally have decreased ET and an increased water yield amount. Oki and Kanae [26] also reached similar conclusions. They considered that the amount of ET in cropland and grazing land accounts for one-third of the total amount of terrestrial ET. Scanlon et al. [27] suggested that rangeland and irrigated land has a large amount of ET and that dryland accounts for a relatively small proportion. LUCC will affect the amount of ET, which in turn affects the amount of water yield [2830], and some scholars have concluded that deforestation will reduce the amount of ET and increase the water yield $[31,32]$.

Throughout the previous studies, some studies have focused on changes in precipitation, some have investigated the impact of changes in vegetation and LUC on the water cycle process, and some have identified a consistent relationship between the regional WYC and precipitation. Based on these results, to simulate the regional gross water resources amount, a few researchers have explored the evolution of the regional WYC and the factors driving these changes. Based on this work, in this paper, factors such as precipitation, rainstorm days, rainless days, NDVI, and LUC are taken into account to analyse the evolution characteristics and genesis of the WYC. The purpose is not only to understand the input and output of water resources in the region but also to identify the mechanisms responsible for changes, to provide a strong scientific basis for the sustainable use and management of regional water resources, and to promote social economic and environmental resource development to ensure more harmonious and stable utilization.

\section{Material and Methods}

2.1. Study Area. The Huang-Huai-Hai River Basin includes three first-class water resources areas, the Yellow River Basin, Huai River Basin, and Hai River Basin. These basins, located within $32^{\circ} 10^{\prime} \sim 43^{\circ} \mathrm{N}$ and $95^{\circ} 53^{\prime} \sim 122^{\circ} 60^{\prime} \mathrm{E}$, are spread across 12 provinces and two municipalities: Gansu, Qinghai, Sichuan, Ningxia, Inner Mongolia, Shaanxi, Shanxi, Hebei, Shandong, Henan, Anhui, Jiangsu, Beijing, and Tianjin. The three major river systems in the region-the Yellow River, Huai River, and Hai River-cross China from west to east and cover a wide range from north to south. The total basin area is large, accounting for approximately $15 \%$ of the land area of China [33]. The overall terrain can be divided from west to east into four levels decreasing in elevation: the Qinghai-Tibet Plateau, the Inner Mongolia Plateau, the Loess Plateau, and the Huang-Huai-Hai Plain $[15,16]$. Climate change in the basin is significant, but the average annual precipitation is $556.0 \mathrm{~mm}$, and the average annual evaporation is $1699.5 \mathrm{~mm}$ [34]. The Huang-Huai-Hai River Basin contains 35\% of the population of China, and its GDP accounts for $32 \%$ of the national 
GDP [17]. This region is an important domestic major food production area and energy base, and it has an important strategic position in China's development. However, the distribution of precipitation in the region is uneven, and interannual changes are frequent. The region is frequently affected by flooding and drought, and the amount of water resources is seriously insufficient. The total amount accounts for only $7.6 \%$ of the country's gross water resources. In the past 20 years, precipitation has decreased greatly, and the average annual precipitation from 1980 to 2000 was generally lower than that from 1956 to 1979 . The available water in the Yellow River Basin, Huai River Basin, and Hai River Basin has decreased by $7.2 \%, 8.5 \%$, and $11.5 \%$, respectively. The average annual water resources for the years of 1956-2000 were 20.04 billion $\mathrm{m}^{3}$, which is $5.3 \%$ lower than the average from 1956 to 1979 , with the Hai River Basin exhibiting a decrease of $12.1 \%$. Due to the common influence of climate change and human activities, the conditions of the underlying surfaces have changed significantly, the amount of water resources has diminished greatly, and the relationship between rainfall and the gross water resources amount has undergone profound changes. Hence, hydrological consistency no longer exists, the water resources situation has become dire, and the management of the water resources is facing great challenges [11].

2.2. Data. The WYC is calculated based on the gross water resources amount and annual precipitation data (1961-2011) collected by the Municipal Water Resources Bulletin. Using ArcGIS to find the centre of the city and generate a point vector with WYC information, we selected the inversed distance weighted (IDW) method [35] for spatial interpolation, and a grid plot with a spatial resolution of $1 \mathrm{~km} \times 1 \mathrm{~km}$ was generated.

The precipitation data were derived from the basic meteorological elements of China's national meteorological stations (V3.0) (2,474 national terrestrial weather stations). The continuous precipitation observation data series (January 1961-December 2011) and precipitation data from the meteorological stations within the four-point range of the HuangHuai-Hai area were used as the basic data for the study. A total of 1,124 sites were selected (Figure 1). We also used the daily precipitation observation data from the meteorological stations to generate the point vector diagram with daily precipitation information and selected the IDW method for spatial interpolation to generate the grid map with daily precipitation information at a spatial resolution of $5 \mathrm{~km} \times$ $5 \mathrm{~km}$. Then, based on the raster data summary from 1982 to 2011 annual growth season (4-10 months) rainless days (daily rainfall less than $5 \mathrm{~mm}$ ), rainstorm days (daily rainfall is greater than or equal to $50 \mathrm{~mm}$ ), and annual precipitation, we obtained the trend and multiyear average.

LUC data were derived from the national LUCC database, and this study analysed the data at a scale of $1: 100,000$ in the Huang-Huai-Hai River Basin for 1980, 1995, 2000, and 2005.

The vegetation data were derived from NASA's normalized difference vegetation index (NDVI) remote sensing image data from 1982 to 2011. The 1982-2006 GIMMS data

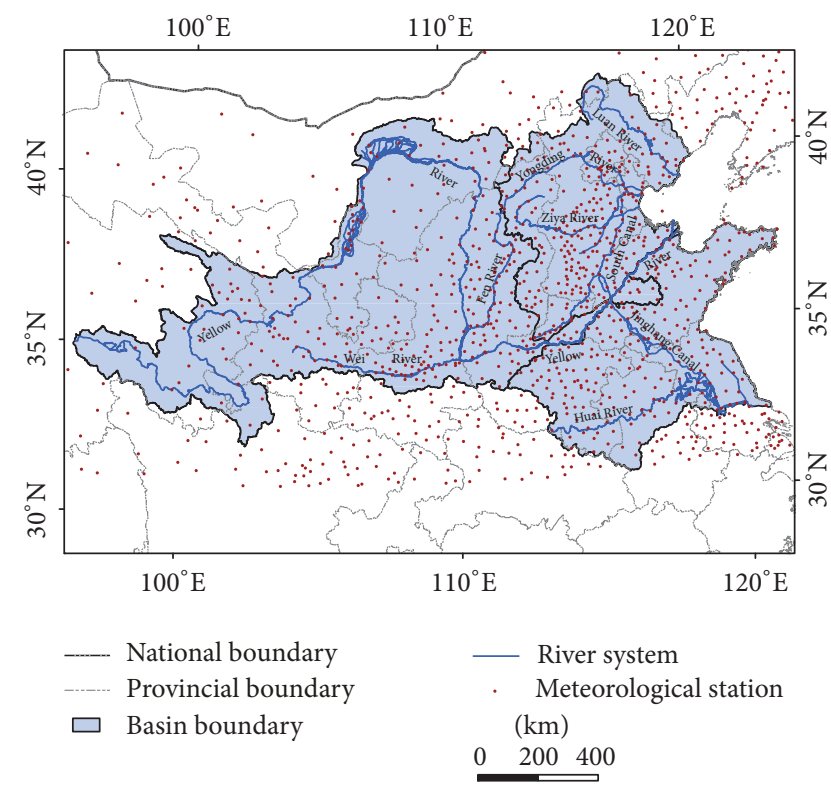

Figure 1: Study area.

and the 2000-2011 MOD13A3 data (these data are half scale with a spatial resolution of $1 \mathrm{~km}$ ) have been subjected to geometric correction, radiation correction, atmospheric correction, and other pretreatments. Since the GIMMS sensors were different from the MODIS sensors, the two sets of data images are biased and misaligned; thus, they were coregistered. Based on the coregistered MODIS data, the GIMMS data were extended to 2011. Then, using the simultaneous data (2000-2006), we calculated the correlation coefficient between the extended data and the measured data [36]. The NDVI mean correlation coefficient of the Huang-Huai-Hai River Basin was found to be above 95\%. After obtaining the NDVI data for the study year, the trend and multiyear annual mean value were calculated to reflect the vegetation coverage during the growing season.

\subsection{Methods}

2.3.1. Climate Trend Method. The general linearity estimation method can be used to calculate the trend of a single grid. We used ArcGIS software, and formula (1) can be used to calculate the trend of each grid, which reflects the distribution of the trend in the entire space.

Based on the grid map of WYC, annual precipitation, number of rainstorm days, number of rainless days, and NDVI in the Huang-Huai-Hai River Basin, this study used the linear regression method to analyse the trends of the above data:

$$
\text { Slope }=\frac{n \times \sum_{i=1}^{n}\left(i \times K_{i}\right)-\sum_{i=1}^{n} i \sum_{i=1}^{n} K_{i}}{n \times \sum_{i=1}^{n} i^{2}-\left(\sum_{i=1}^{n} i\right)^{2}} .
$$

The slope represents the time series change. When the slope is $>0$, the trend of the time series is positive, and the values increase over time; otherwise, it is negative. The variable, $i$, is 
the year number; for example, when calculating the trend for 1961-2011, $i=1$ for 1961, $i=2$ for 1962, and so forth $K_{i}$ is the value of year $i$, and $n$ is the cumulative number of years in the study period; for example, when calculating the trend from 1982 to $2011, n=30$.

2.3.2. Mann-Kendall Test. The Mann-Kendall (M-K) test is a nonparametric statistical test method that can be used to analyse the trend of the time series and mutation. The advantages of a nonparametric test, also known as a no distribution test, are that the sample does not require a certain distribution and that interference does not result from a small number of outliers. Such a test can objectively characterize the overall change trend of a sequence of samples. The M$\mathrm{K}$ method was originally proposed by Mann and Kendall, and, after continuous improvement and perfection, it is now recommended that meteorological organizations apply it in the analysis of time series trends. This test has been widely used for determining the trends in meteorological and runoff data around the world. In this study, the M-K test method was used to test the significance of the WYC trend to obtain more accurate trend characteristics.

2.3.3. Land Use Transfer Matrix Analysis. The transfer matrix is a common method used around the world to reveal the direction of change between LUC types, and it can reflect the structural characteristics of LUCC in a comprehensive and concrete way, reflecting the direction of LUCC related to human activities $[37,38]$. This method is derived from the quantitative analysis of a system state and state transition in system analysis, which reflects the process of transitioning a substable system from $T$ to $T+1$ in a certain time interval, in order to better understand the spatial and temporal evolution of the LUC pattern [38]. The meaning of the expression of the elements in the matrix is very clear, and there is a clear statistical relationship between the ranks, usually given in the form of a table. The significance of the transfer matrix is that it not only reflects the structure of the LUC type during each period but can also reflect the change in the transition between different types of land. It can also provide a better understanding of the source and composition of the LUC transition [37, 38]. The mathematical form of the transfer matrix is as follows:

$$
S_{i j}=\left|\begin{array}{cccc}
S_{11} & S_{12} & \cdots & S_{1 n} \\
S_{21} & S_{22} & \cdots & S_{2 n} \\
\vdots & \vdots & \vdots & \vdots \\
S_{n 1} & S_{n 2} & \cdots & S_{n n}
\end{array}\right| \text {, }
$$

where $S$ is the area; $n$ is the number of LUC types; $i$ and $j$ are the LUC types at the beginning and end of the study period, respectively; and $S_{i j}$ refers to class $i$ land converted into class $j$ land. From the meaning of the transfer matrix, we can see that the sum of row $i$ is the area of LUC class $i$ for the base period, and column $j$ is the area of LUC $j$ for the study period.
At present, the vector used in the land use state transfer matrix can be the LUC type area or the probability of LUC type conversion into the final LUC type, which is called a Markov transition probability matrix [37]. In this study, the former was used to analyse the LUC type transition in the Huang-Huai-Hai River Basin.

2.3.4. Spatial Clustering Analysis. Clustering involves classifying data objects into multiple classes or clusters. There is a high degree of similarity between objects in the same cluster, and objects in different clusters are different from each other. The degree of dissimilarity is calculated from the attribute value of the described object, and the distance is often used as a measure. The most common distance is the Euclidean distance, defined as follows:

$$
\begin{aligned}
& d(i, j) \\
& \quad=\sqrt{\left|x_{i 1}-x_{j 1}\right|^{2}+\left|x_{i 2}-x_{j 2}\right|^{2}+\cdots+\left|x_{i p}-x_{j p}\right|^{2}} .
\end{aligned}
$$

$i=\left(X_{i 1}, X_{i 2}, \ldots, X_{i p}\right)$ and $j=\left(X_{j 1}, X_{j 2}, \ldots, X_{j p}\right)$ are two $p$-dimensional data objects.

In this paper, considering the causes of the change in WYC in different areas, we have performed four cluster analyses. The first is a clustering of the grid map of the WYC trend and precipitation trend during 1961-2011. The second is a clustering of the grid map of the WYC trend, precipitation trend, rainstorm days trend, rainless days trend, and NDVI trend during 1961-2011. The third is a clustering of the grid map of the multiyear average WYC and multiyear average precipitation during 1982-2011. The fourth is a clustering of the grid map of the multiyear average WYC, multiyear average precipitation, multiyear rainstorm days, multiyear rainless days, and multiyear NDVI value during 1982-2011. Using the ArcGIS spatial analysis tool, the Euclidean shortest distance clustering method was used to cluster the above grid, and the eigenvalues of the elements in each classification were obtained and analysed.

\section{Results and Analysis}

3.1. Temporal Variations in the WYC. Figure 2(a) shows the distribution of the actual WYC in the Huang-Huai-Hai River Basin from 1961 to 2011. To facilitate the spatial comparison, we normalized the actual WYC shown in Figure 2(b) with the following standardization formula:

$$
\mathrm{WYC}_{\text {norm }}=\frac{\mathrm{WYC}-\mathrm{WYC}_{\min }}{\mathrm{WYC}_{\max }-\mathrm{WYC}_{\min }},
$$

where $\mathrm{WYC}_{\text {norm }}$ is the normalized WYC, $\mathrm{WYC}_{\min }$ is the minimum value of the long-sequence WYC during 1961-2011, and $\mathrm{WYC}_{\max }$ is the maximum value of the long-sequence WYC during 1961-2011.

From the temporal variations of the actual WYC during the period from 1961 to 2011, the variation range of the WYC in the Huang-Huai-Hai River Basin was relatively small. The trend was between $-0.05 / 10 \mathrm{a}$ and $0.04 / 10 \mathrm{a}$, and the trend of the normalized WYC was between $-0.15 / 10 \mathrm{a}$ and $0.12 / 10 \mathrm{a}$. As 


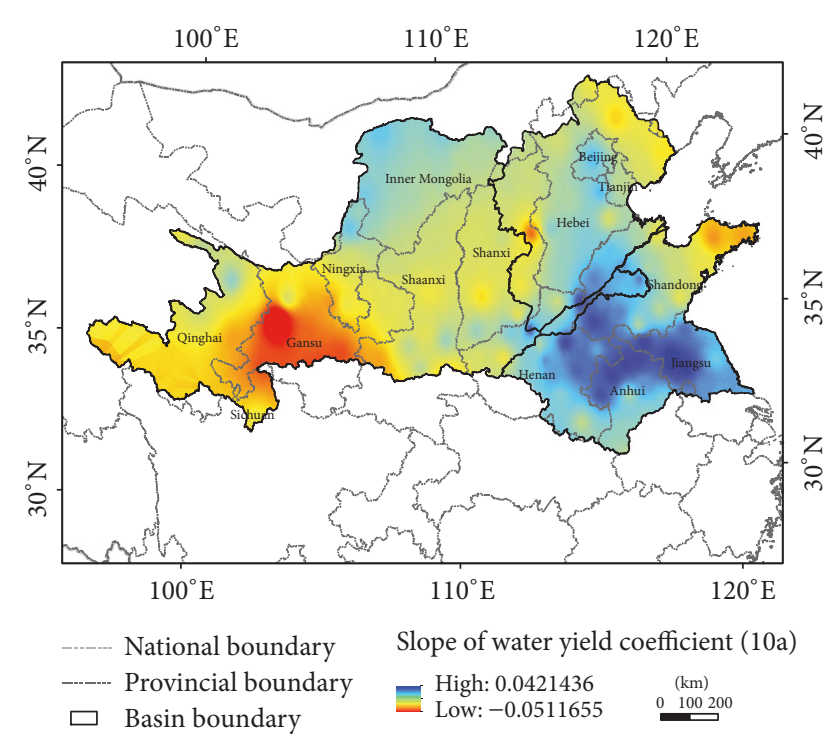

(a)

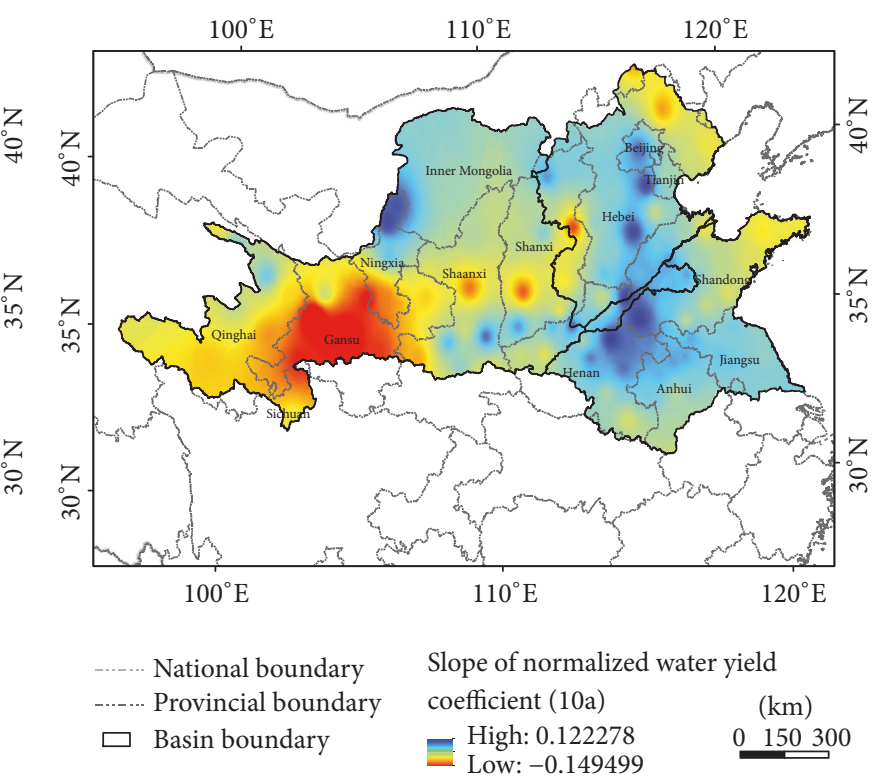

(b)

Figure 2: (a) Trend of the actual WYC from 1961 to 2011. (b) Trend of the normalized WYC from 1961 to 2011.

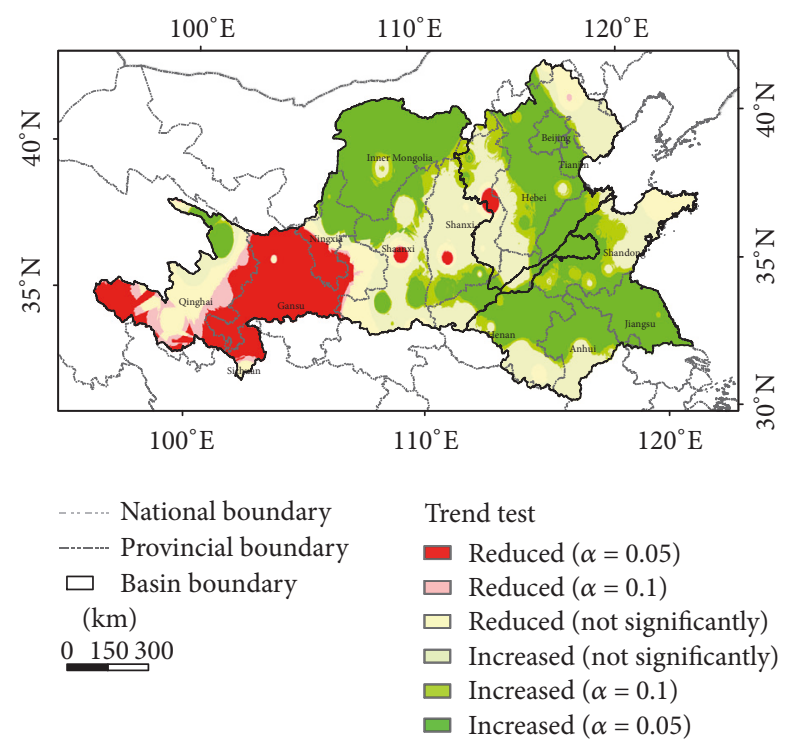

FIGURE 3: Trend test of the WYC trend from 1961 to 2011.

shown in Figure 3, most of the western part of the Yellow River Basin has a negative trend, and the southern part of Gansu Province has a significant negative trend (representing the largest negative trend), with the $\mathrm{M}-\mathrm{K}$ test indicating significance at a level of $\alpha=0.05$. The northern part of the Yellow River Basin (central Inner Mongolia Autonomous Region) exhibited a significant positive trend at a significance level of $\alpha=0.05$. The changes in the central part of the Yellow River Basin and the western part of the Hai River Basin were relatively small and stable, and the trend did not pass the significance test. There was a significant positive trend in the area between Tongguan Station and Lijin Station in the Yellow River Basin, at a significance level of $\alpha=0.05$ according to the $\mathrm{M}-\mathrm{K}$ test. The northern part of the Hai River Basin (Chengde City, Qinhuangdao City, and Tangshan City in northern Hebei Province) showed a slight negative trend, but the trend was not large. The middle of the Hai River Basin (Beijing City and Langfang City) and the southern portion of the Hai River Basin (Shandong Province) showed clear positive trends, at a significance level of $\alpha=0.05$. In addition to a negative trend for Shandong Peninsula, most of the Huai River Basin exhibited an increasing trend, especially in the eastern part of Henan Province, western Shandong Province, northern Anhui Province, and northern Jiangsu Province, at a significance level of $\alpha=0.05$. These regions exhibited the largest increase in the rate of change.

3.2. Causes of the Temporal Variations. According to the definition of WYC, the main factor affecting the variation in WYC is hypothesized to be precipitation; thus, we first analyse the precipitation trend from 1961 to 2011 (Figure 4). The central part of the Yellow River Basin, most of the Hai River Basin, and the Shandong Peninsula in the Huai River Basin all showed negative trends. The northern and western parts of the Yellow River Basin (Qinghai province) and the southern part of the Huai River Basin showed positive trends. After clustering the WYC and the precipitation trend, a map of cluster distribution between WYC and precipitation trend (Figure 5) was obtained and was generally divided into five types. The average relationships between the two factors in various regions are shown in Figure 6. The first (red), fourth (light green), and fifth (green) types all showed good positive correlations between the two factors; that is, when the precipitation increases, the WYC increases. The second (orange) and third (yellow) types showed negative correlations; that is, when the precipitation decreased, the WYC increased. 


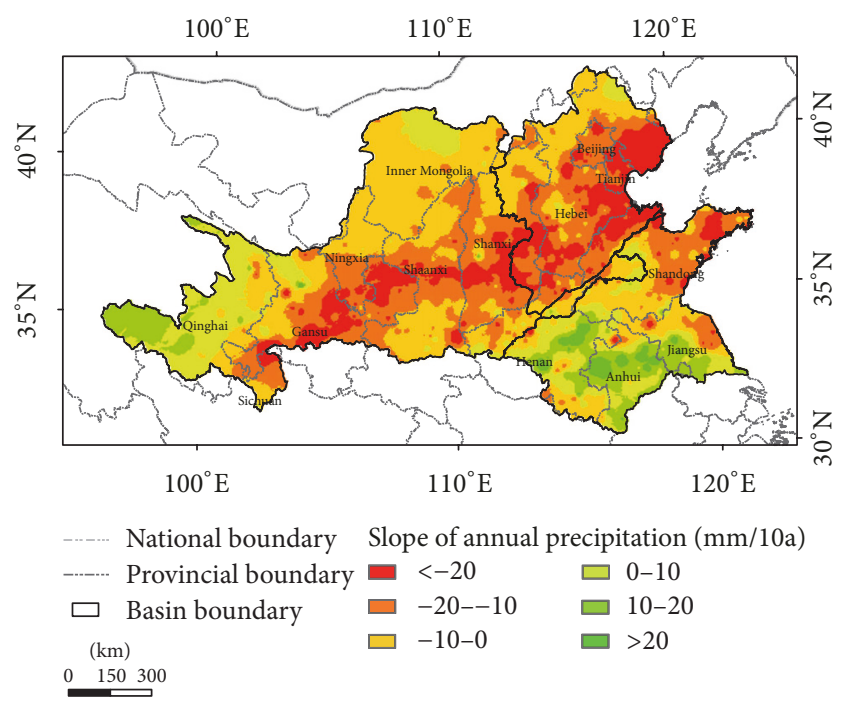

FIGURE 4: Precipitation trends from 1961 to 2011.

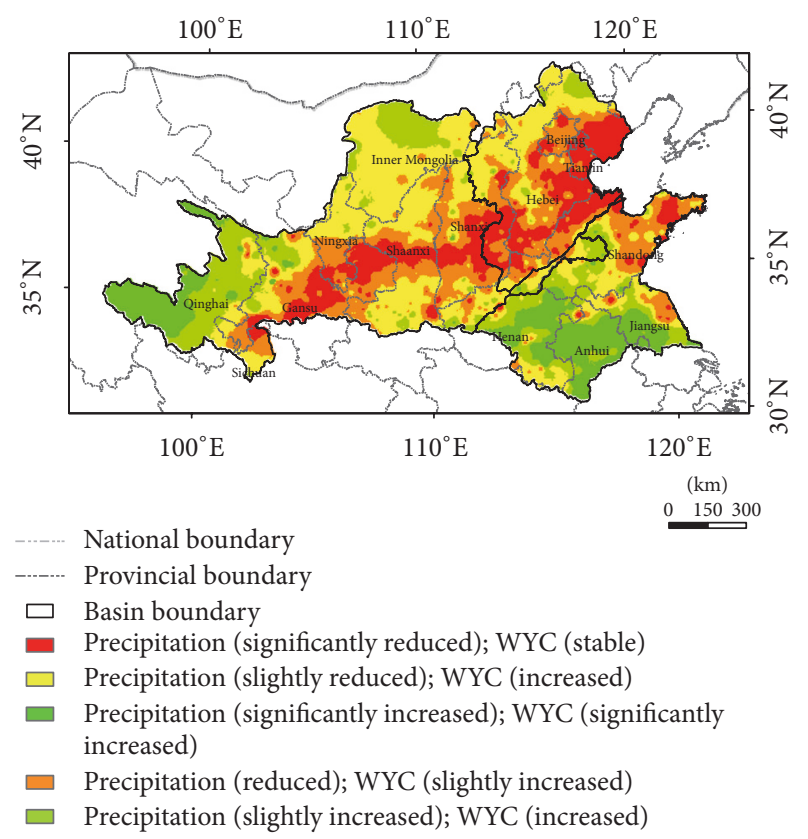

Figure 5: Cluster distribution.

From the first type to the fifth type, the precipitation trends gradually increase from negative to positive, but the changes in WYC are inconsistent. From the third to the fourth type, the precipitation increased from a negative trend of $-6.9 \mathrm{~mm} / 10$ a to a slight positive trend of $0.9 \mathrm{~mm} / 10 \mathrm{a}$, whereas the WYC changed from $0.027 \mathrm{~mm} / 10 \mathrm{a}$ to $0.022 \mathrm{~mm} / 10 \mathrm{a}$, representing a reduction in the rate of increase. In the first to the third type, the precipitation decreases, but the WYC increases or slightly decreases. Therefore, the above analysis shows that both precipitation and other factors, such as other precipitation characteristics and other underlying surface conditions, affect the WYC.

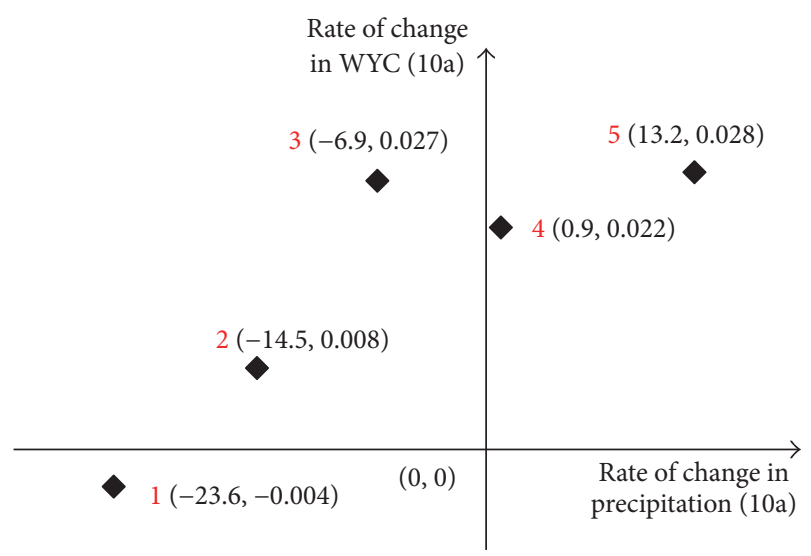

FIGURE 6: Coupled relationships between the trends of WYC and precipitation from 1961 to 2011 .

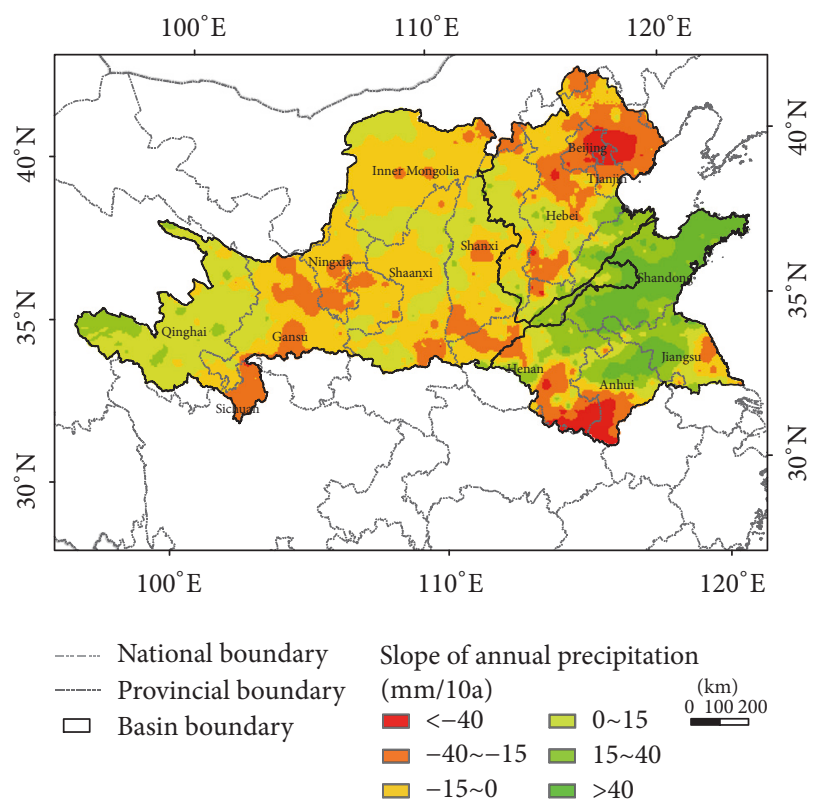

FIGURE 7: Rate of change in precipitation from 1982 to 2011.

Because the satellite remote sensing image data records are from the 1980s, to analyse the influence of other underlying factors on the WYC, such as vegetation and LUC, we selected 1982 to 2011 as the research time period, and we used the rates of change in precipitation (Figure 7), rainstorm days (Figure 8), rainless days (Figure 9), NDVI (Figure 10), and normalized WYC (Figure 11) to conduct a comprehensive comparative analysis. Using the ArcGIS spatial analysis tool to obtain the cluster distribution map via the Euclidean shortest distance clustering method (Figure 12), the study area can be generally divided into five types. The average of the rates of change in the WYC and other four factors in each region was calculated, then the average rate of change in each factor was taken as the independent variable, and the average rate of change in the WYC was taken as the dependent variable to generate a correlation diagram (Figure 13). At the same time, the transition matrix (Table 1) of LUC in 1980, 


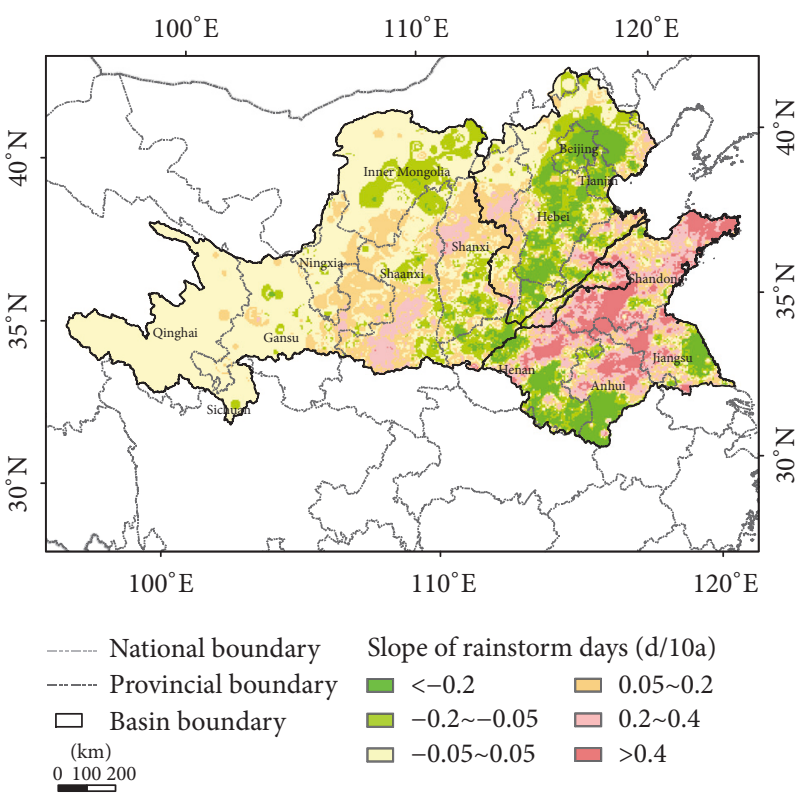

FIGURE 8: Rate of change in rainstorm days from 1982 to 2011.

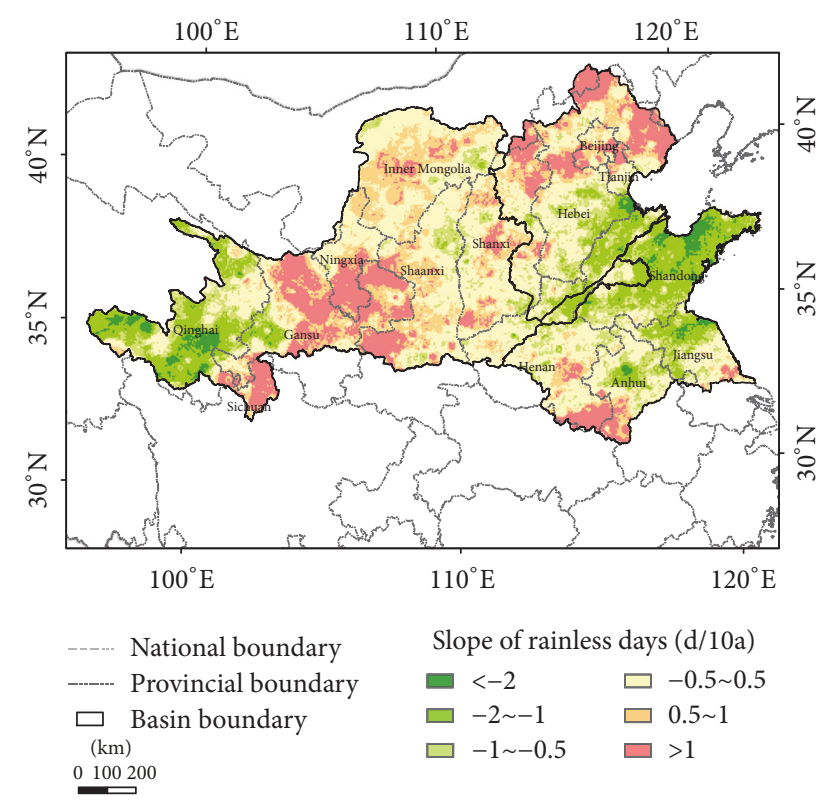

FIGURE 9: Rate of change in rainless days from 1982 to 2011.

1995, 2000, and 2005 (Figure 14) was constructed for the five types, and the change in each LUC type was analysed.

For the first three types of areas, the first and second types are generally located in the central and northern parts of the Huai River, and the third type is mainly located in the central and western parts of the Yellow River Basin. In Figures 13(a) and 13(b), the three points representing the three types are all located in the first quadrant, and the horizontal and vertical axis values gradually decrease from the first to the third type. For the first to the third types, the average trends for standardized WYC are $0.184 / 10 \mathrm{a}, 0.087 / 10 \mathrm{a}$, and $0.065 / 10 \mathrm{a}$, respectively; the trends for precipitation are

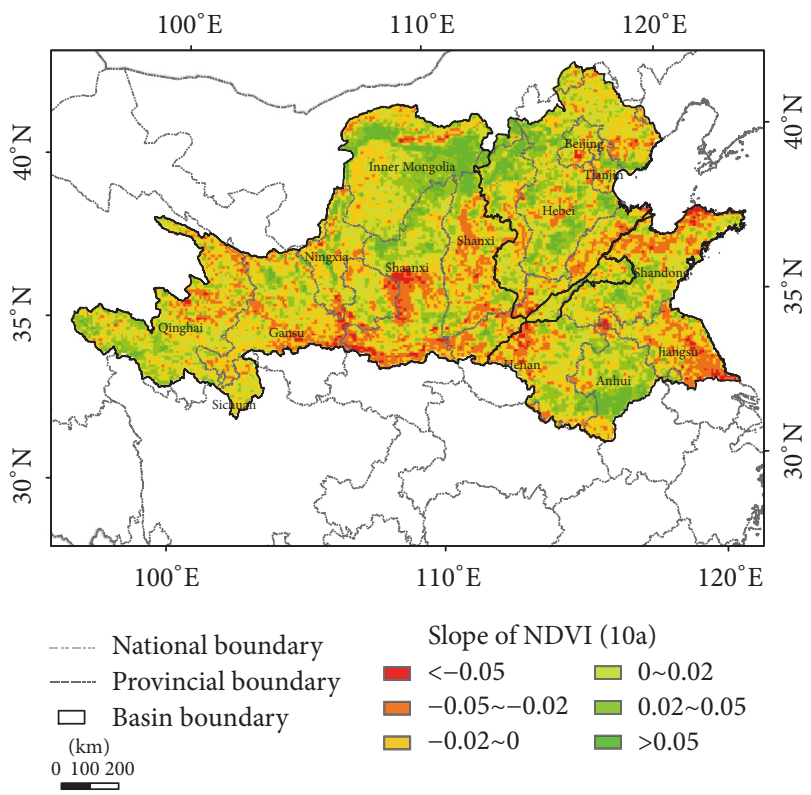

FIGURE 10: Rate of change in NDVI from 1982 to 2011.

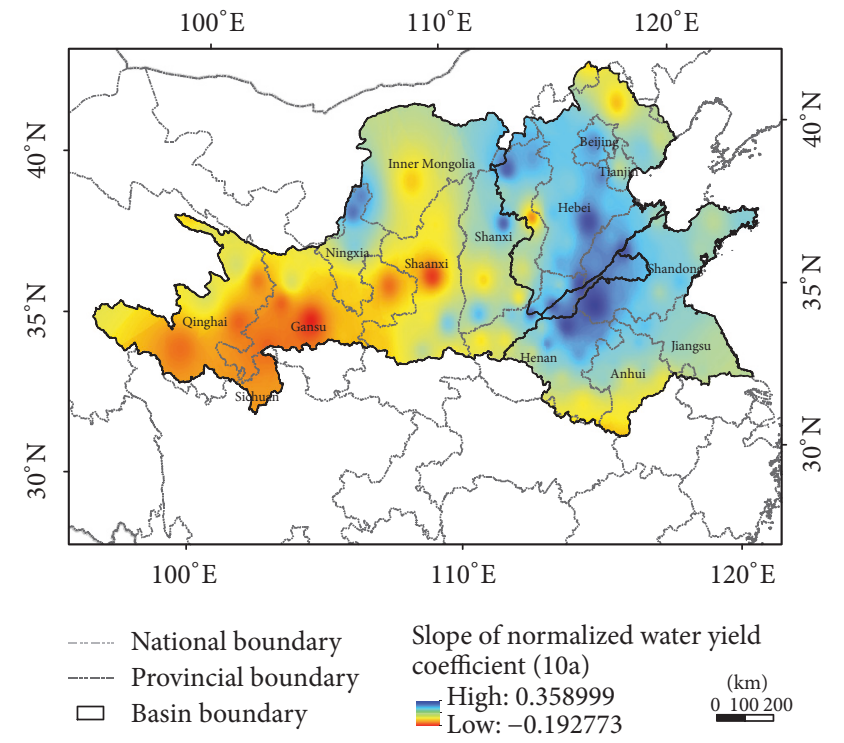

FIGURE 11: Rate of change in the normalized WYC from 1982 to 2011.

$51.15 \mathrm{~mm} / 10 \mathrm{a}, 25.46 \mathrm{~mm} / 10 \mathrm{a}$, and $6.43 \mathrm{~mm} / 10 \mathrm{a}$, respectively; and the trends for rainstorm days are $0.38 \mathrm{~d} / 10 \mathrm{a}, 0.18 \mathrm{~d} / 10 \mathrm{a}$, and $0.05 \mathrm{~d} / 10 \mathrm{a}$, respectively. In Figure $13(\mathrm{c})$, the three points are located in the second quadrant, with abscissa values of $-1.26 \mathrm{~d} / 10 \mathrm{a},-0.94 \mathrm{~d} / 10 \mathrm{a}$, and $-0.47 \mathrm{~d} / 10 \mathrm{a}$, respectively, indicating decreases in the absolute values. In Figure 13(d), the abscissa values of the three points are $0.014 / 10 \mathrm{a}, 0.021 / 10 \mathrm{a}$, and $0.020 / 10 \mathrm{a}$, broadly indicating that as the WYC trend becomes smaller the NDVI trend becomes larger. In the first type, arable land accounted for the largest proportion in the region, close to $70 \%$, but the area did not change much during the study period. Grassland decreased from $11,172 \mathrm{~km}^{2}$ to $8,269 \mathrm{~km}^{2}$, representing a decrease of $25.98 \%$. The area of 


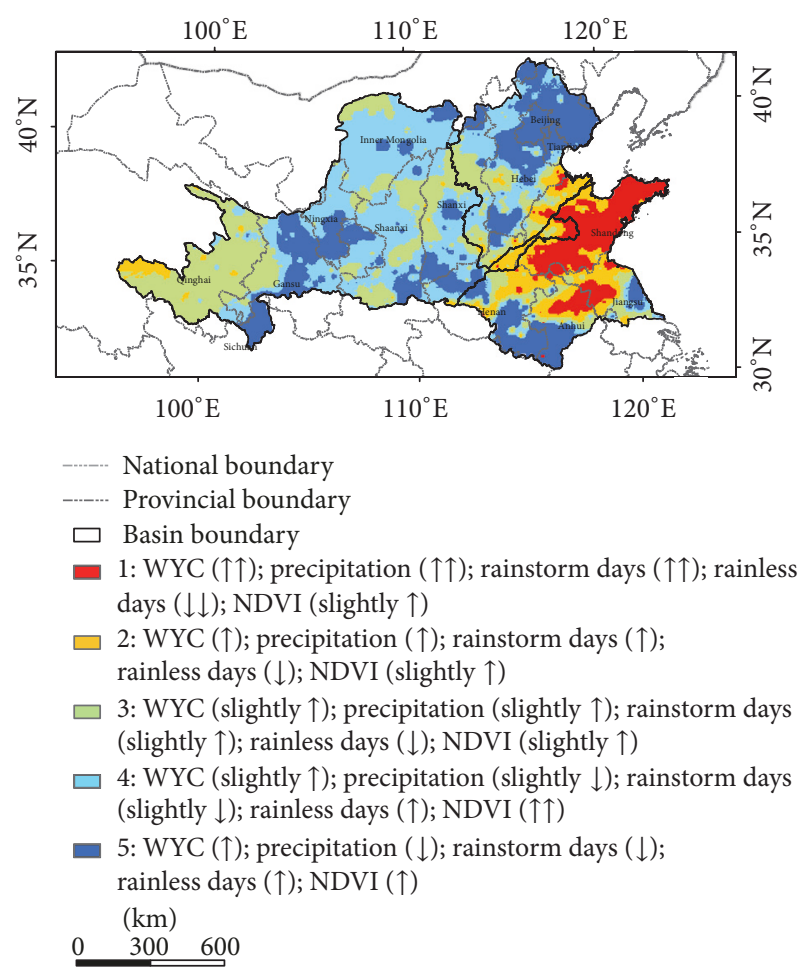

FIGURE 12: Cluster distribution.

water increased by $21.73 \%$, but its proportion of the total area was relatively small at approximately $4 \%$ and showed little change. The area of urban land increased by $10.24 \%$, that is, approximately $1449.19 \mathrm{~km}^{2}$, and its proportion of the total area was approximately $10 \%$. In the second type, arable land accounted for the largest proportion of $67 \%$, and it decreased by only $0.24 \%$. Woodland increased by $9.54 \%$, grassland decreased by $17.43 \%$, urban land increased by $12.42 \%$, and the other LUC types changed a little. In the third type, grassland, arable land, and woodland accounted for $42 \%$, $31 \%$, and $14 \%$, respectively, but the changes were insignificant for the grassland (a decrease of 1.5\%) and the arable land (a decrease of 1.66\%). The area of urban land increased by $23.86 \%$, corresponding to approximately $2790.55 \mathrm{~km}^{2}$.

The analysis of the three region types shows that the variation in precipitation characteristics is consistent with the WYC. For the rate of change, there are positive correlations between the WYC and precipitation and between the WYC and rainstorm days. The correlations between the WYC and rainless days are negative. Although NDVI is positively correlated with the rate of the WYC, the trend of NDVI is negatively correlated with that of the WYC; hence, the slower the rise in NDVI, the faster the rise in WYC. This pattern is slightly unusual in the second and third regions, considering that only the proportion of urban land in the third type increased, that the amount of ET increased, and that the changes in other LUC types were small. In the second type, the urban land area has increased, but the grassland area has decreased. Because of the interaction of these two factors, the ET changes were not obvious. These factors eventually led to a lower rate of increase in the WYC in the third type than in the second type, despite identical NDVI trends.

For the fourth and fifth regions, shown in Figures 13(a) and 13(b), the points of the two regions are located in the second quadrant for both precipitation and rainstorm days, and as the value of the independent variable decreases, the value of the dependent variable increases. For rainless days, the points representing the two regions are located in the first quadrant, indicating that the dependent variable increases with increases in the independent variable. The NDVI trend is the same as in the first three types. The average trends for standardized WYC were $0.062 / 10 \mathrm{a}$ and $0.105 / 10 \mathrm{a}$, the trends for precipitation were $-5.23 \mathrm{~mm} / 10 \mathrm{a}$ and $-24.45 \mathrm{~mm} / 10 \mathrm{a}$, the trends for rainstorm days were $-0.01 \mathrm{~d} / 10 \mathrm{a}$ and $-0.13 / 10 \mathrm{a}$, the trends for rainless days were $0.41 / 10 \mathrm{a}$ and $0.83 / 10 \mathrm{a}$, and the trends for NDVI were $0.086 / 10 \mathrm{a}$ and $0.05 / 10 \mathrm{a}$. In the fourth region, the LUC types mainly include grassland and arable land, accounting for approximately 39\% and 34\%, respectively, which decreased in area by $3302.22 \mathrm{~km}^{2}$ and $2903.07 \mathrm{~km}^{2}$, respectively. Woodland increased by $3283.34 \mathrm{~km}^{2}$, and urban land increased by $2961.19 \mathrm{~km}^{2}$. In the fifth region, arable land, grassland, and woodland accounted for $45 \%, 27 \%$, and $18 \%$, respectively; arable land decreased by $3951.33 \mathrm{~km}^{2}(2.45 \%)$, and grassland decreased by $5644.73 \mathrm{~km}^{2}(5.71 \%)$. In contrast, woodland increased by $4245.78 \mathrm{~km}^{2}$ (7.03\%), and urban land increased by $4898.15 \mathrm{~km}^{2}$ (31.66\%). In general, the relationship between the different LUC types in terms of ET is as follows: water area $>$ arable land $>$ woodland $>$ grassland $>$ urban land $[39,40]$. In both the fourth and fifth areas, the area of arable land and grassland decreased, while that of woodland and urban land increased, resulting in an overall decrease in ET and an increase in the water yield capacity. Therefore, even though the precipitation and rainstorm days decreased and rainless days increased, the WYC still rose.

Based on the above analysis, the average WYC of the five types of regions generally increased and was relatively stable under the influence of the various factors. The impact of precipitation characteristics can be divided into two extreme cases. In one case, the changes in LUC types have less effect on the WYC than increases in precipitation, rainfall intensity, and rainy season duration. In the other case, the changes in LUC types have a greater impact due to decreases in the precipitation, rainfall intensity, and rainy season duration. When the area of grassland and arable land decreased, the amount of ET decreased. Although the amount of woodland and urban land increased, the amount of ET was lower than that under arable land and grassland. These changes resulted in a decrease in total ET, so the WYC was not greatly affected. In both cases, changes in vegetation coverage had minimal effects on the WYC, demonstrating that slower rates of change in the NDVI were associated with faster rates of change in the WYC.

3.3. Spatial Patterns of WYC. According to Figure 15, the distribution of WYC is fairly regular, generally increasing from the north to the surrounding area. The area with WYC values of $<0.1$ accounts for $29.7 \%$, most of which belongs to 


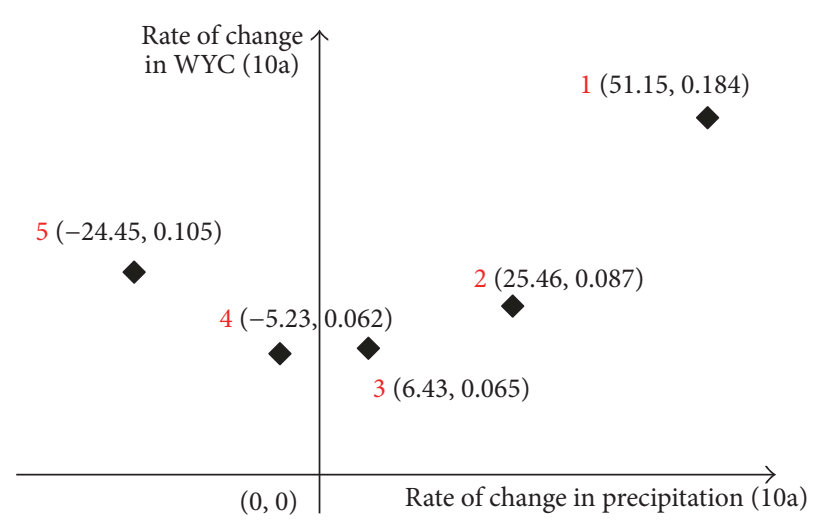

(a)

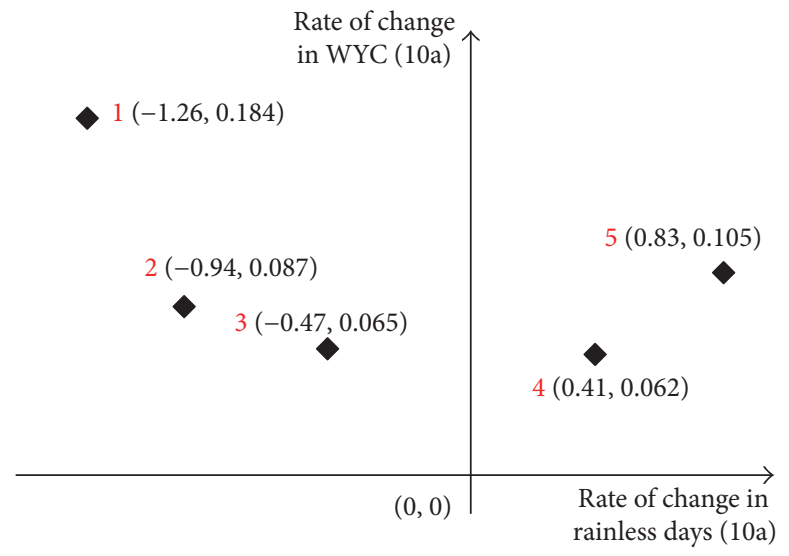

(c)

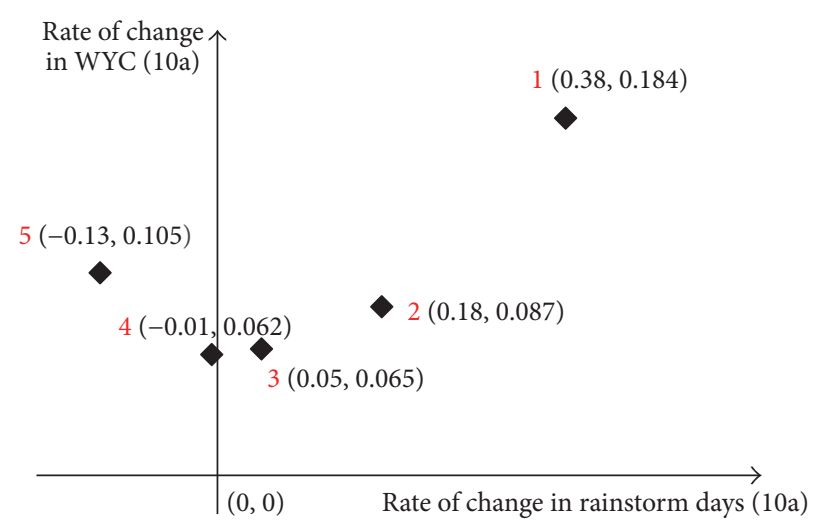

(b)

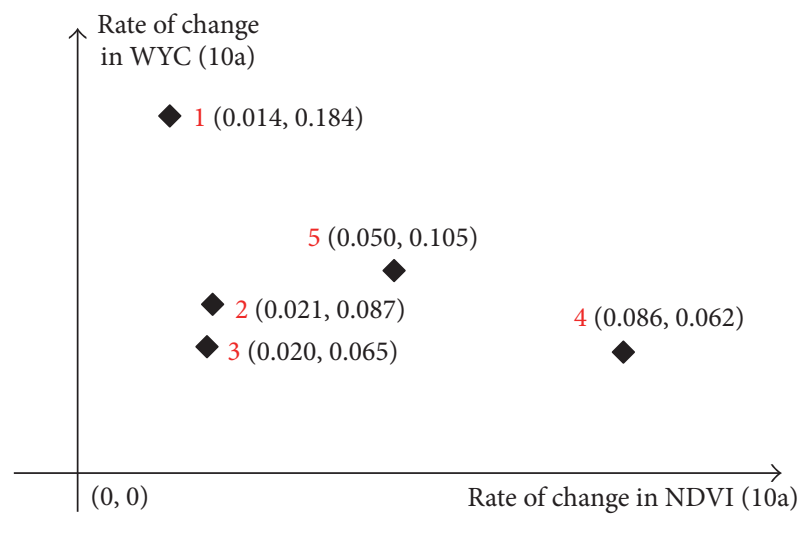

(d)

FIGURE 13: The coupled relationships between WYC and four factors from 1982 to 2011.

the temperate continental climate. This area is mainly located in the middle and northern portions of the Yellow River Basin (Ningxia, central Inner Mongolia, eastern Gansu, northern Shaanxi, and northwestern Shanxi) and in the middle and northwestern portions of the Hai River Basin (northern Shanxi and northwestern Hebei). The area with WYC values between 0.1 and 0.2 accounts for $38.1 \%$, most of which belongs to the monsoon climate of the middle latitudes. This area is mainly in the middle and southern portions of the Yellow River Basin, the western and northern portions of the Huai River Basin and most of the Hai River Basin. The area with WYC values between 0.2 and 0.3 accounts for $22.1 \%$ and represents part of the monsoon climate of the middle latitudes and a portion of alpine climate. This area is mainly located in the Huai River Basin (Shandong Peninsula, southeastern and northern Jiangsu, northern Anhui, and central Henan) and in the southern and northwestern Yellow River Basin (northern Qinghai). The area with WYC values between 0.3 and 0.4 accounts for $8.8 \%$ and represents part of the subtropical monsoon climate and part of the alpine climate. This area is mainly located in the southwestern Yellow River Basin (southeastern Qinghai and southwestern Gansu) and the southwestern Huai River Basin (southern Henan and western Anhui). The areas with WYC values of $0.4-0.5$ and $>0.5$ account for $1.0 \%$ and $0.4 \%$, respectively, and represent part of the subtropical monsoon climate and part of the alpine climate. These areas are mainly located in the southwestern Yellow River Basin (Sichuan Province) and in the southern Huai River Basin (Anhui Province and south of Lu'an City).

3.4. Causes of the Spatial Patterns. The spatial distribution of the average precipitation from 1961 to 2011 is shown in Figure 16. In the Huang-Huai-Hai River Basin, it is evenly distributed and gradually increases from the northwestern interior to the southeastern coast. The average annual precipitation is less than $300 \mathrm{~mm}$ in the Hetao Plain in the northwestern Huang-Huai-Hai River Basin but is greater than $800 \mathrm{~mm}$ in the North China Plain. By clustering the multiyear average WYC and the multiyear average precipitation, a cluster distribution map was obtained (Figure 17), and the results are broadly divided into five types. The average value of the WYC and precipitation increases from the first to the fifth types, and the correlation between the two factors is shown in Figure 18. $R^{2}$ of the linear trend is 0.94 , indicating that the spatial distributions of WYC and precipitation correlate well.

Because the satellite remote sensing image data are from the 1980s, we combined the multiyear average WYC (Figure 19), precipitation (Figure 20), rainstorm days (Figure 21), 


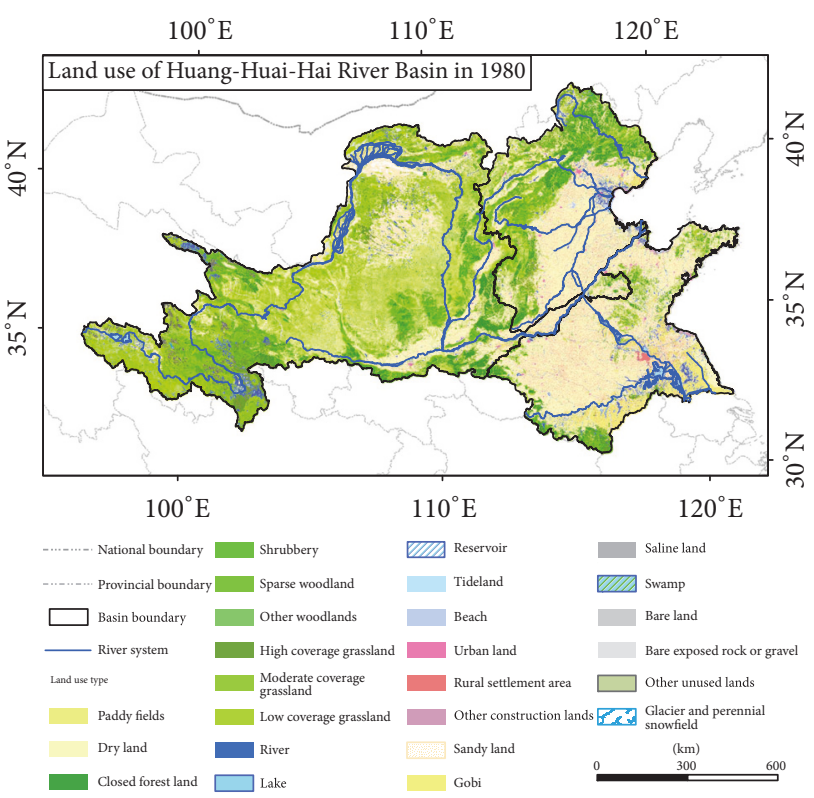

(a)

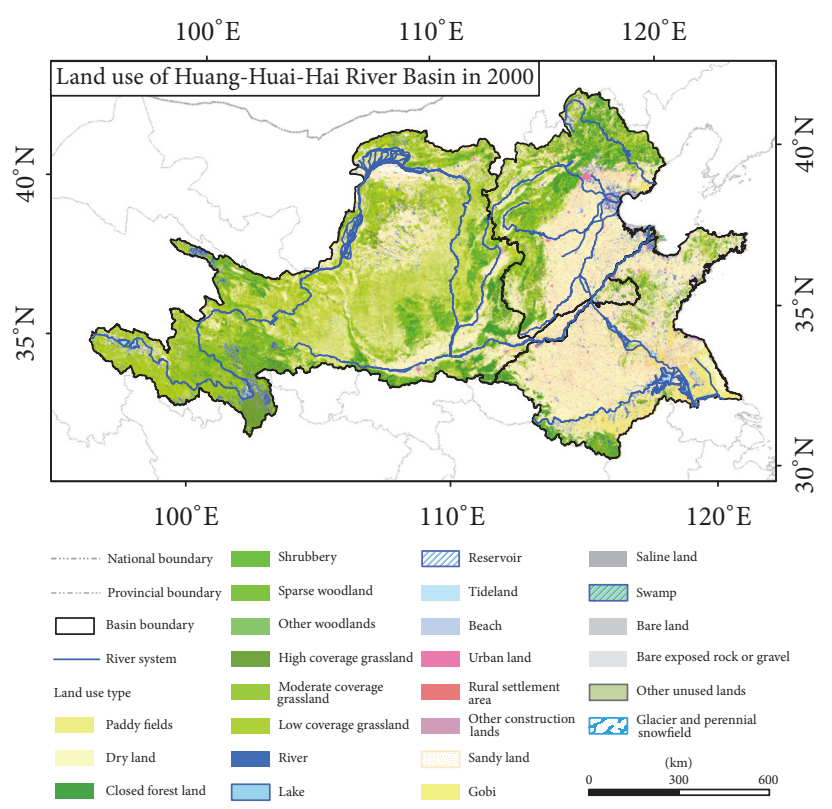

(c)

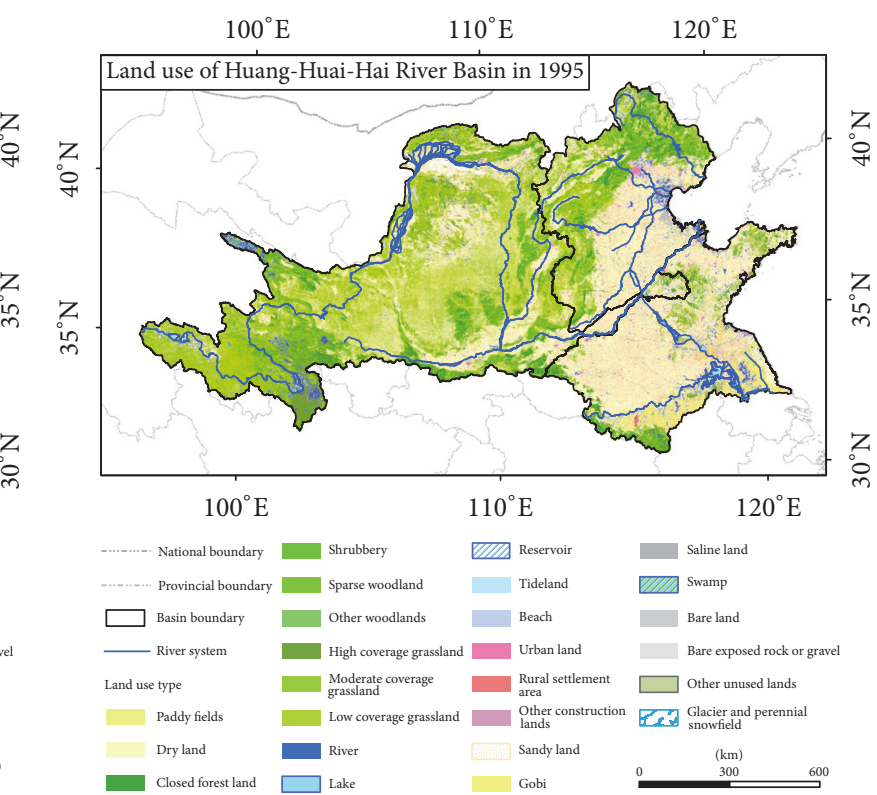

(b)

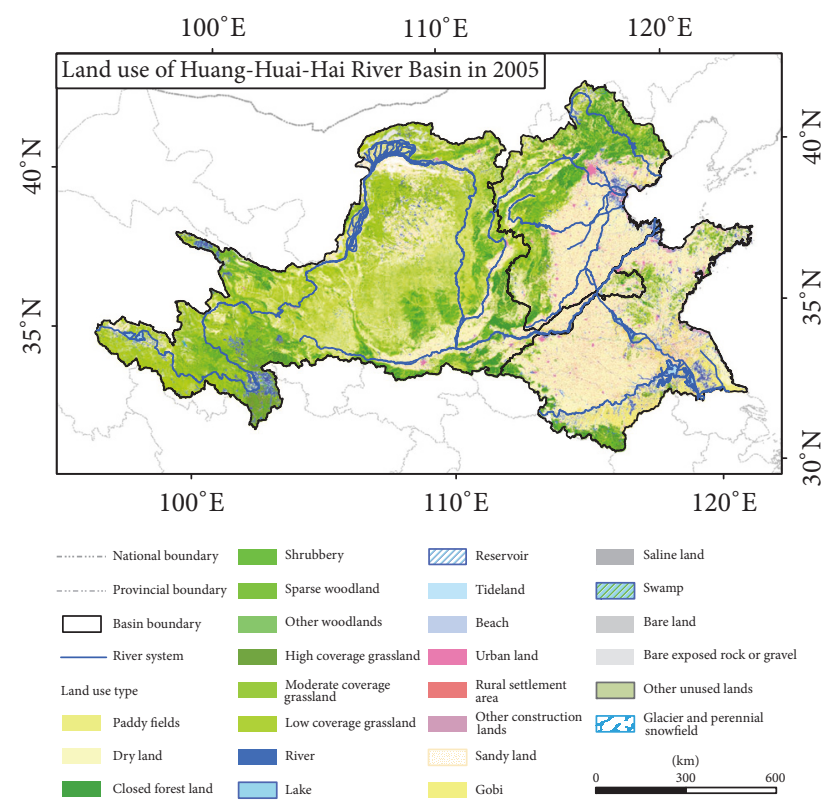

(d)

Figure 14: Land use/cover change in the Huang-Huai-Hai River Basin from 1980 to 2005.

rainless days (Figure 22), and NDVI (Figure 23) to analyse the causes of the spatial distribution of the WYC. As shown in the NDVI distribution map, the vegetation coverage was low in the Yellow River Basin in the northern region but good in the other areas. The number of rainstorms exhibited a clear decrease in the Huai River Basin to the Hai River Basin and in the Yellow River Basin. The distribution of rainless days was also divided into three categories. The number of rainless days was largest in the Hetao Plain in the northern part of the Yellow River Basin and relatively small in the southern part of the Huai River Basin and in the Yellow River Basin in Sichuan Province. The above factors were clustered using the Euclidean shortest distance clustering method, and the cluster distribution map was obtained (Figure 24).

As shown on the map, the distributions of all parameters are very regular, and from the northwestern interior to the southeastern coast, the distributions can be divided into five types. The average value of WYC in the first to the fifth types ranges from 0.08 to 0.28 . The average precipitation ranges from $220 \mathrm{~mm}$ to $790 \mathrm{~mm}$, and the average value of NDVI ranges from 0.20 to 0.53 . The average number of rainstorm days gradually increases from 4 days to 135 days, and the 
TABLE 1: Land use/cover change.

\begin{tabular}{|c|c|c|c|c|c|c|c|}
\hline Classification & Land use type & $\begin{array}{c}\text { Area in } 1980 \\
\left(\mathrm{~km}^{2}\right)\end{array}$ & $\begin{array}{c}\text { Proportion in } \\
1980 \\
\end{array}$ & $\begin{array}{c}\text { Area in } 2005 \\
\left(\mathrm{~km}^{2}\right)\end{array}$ & $\begin{array}{c}\text { Proportion in } \\
2005 \\
\end{array}$ & $\begin{array}{c}\text { Area of } \\
\text { change }\left(\mathrm{km}^{2}\right)\end{array}$ & $\begin{array}{l}\text { Percentage } \\
\text { change (\%) }\end{array}$ \\
\hline \multirow{7}{*}{ (1) } & 1: arable land & 86139 & 68.47 & 87052 & 69.20 & 912.69 & 1.06 \\
\hline & 2: woodland & 8911 & 7.08 & 9144 & 7.27 & 233.07 & 2.62 \\
\hline & 3: grassland & 11172 & 8.88 & 8269 & 6.57 & -2902.49 & -25.98 \\
\hline & 4: water & 4485 & 3.57 & 5460 & 4.34 & 974.70 & 21.73 \\
\hline & 5: urban land & 14146 & 11.25 & 15596 & 12.40 & 1449.19 & 10.24 \\
\hline & 6: unused land & 947 & 0.75 & 280 & 0.22 & -667.16 & -70.43 \\
\hline & SUM & 125801 & 100.00 & 125801 & 100.00 & 0.00 & \\
\hline \multirow{7}{*}{ (2) } & 1: Arable land & 91549 & 67.37 & 91330 & 67.21 & -218.95 & -0.24 \\
\hline & 2: woodland & 3840 & 2.83 & 4207 & 3.10 & 366.40 & 9.54 \\
\hline & 3: grassland & 13248 & 9.75 & 10939 & 8.05 & -2309.45 & -17.43 \\
\hline & 4: water & 6078 & 4.47 & 6062 & 4.46 & -15.77 & -0.26 \\
\hline & 5: urban land & 16161 & 11.89 & 18168 & 13.37 & 2006.70 & 12.42 \\
\hline & 6: unused land & 5008 & 3.69 & 5179 & 3.81 & 171.07 & 3.42 \\
\hline & SUM & 135884 & 100.00 & 135884 & 100.00 & 0.00 & \\
\hline \multirow{7}{*}{ (3) } & 1: arable land & 115898 & 31.69 & 113976 & 31.17 & -1921.66 & -1.66 \\
\hline & 2: woodland & 50051 & 13.69 & 50148 & 13.71 & 96.99 & 0.19 \\
\hline & 3: grassland & 155794 & 42.60 & 153464 & 41.97 & -2329.74 & -1.50 \\
\hline & 4: water & 7410 & 2.03 & 7622 & 2.08 & 211.96 & 2.86 \\
\hline & 5: urban land & 11694 & 3.20 & 14485 & 3.96 & 2790.55 & 23.86 \\
\hline & 6: unused land & 24846 & 6.79 & 25998 & 7.11 & 1151.90 & 4.64 \\
\hline & SUM & 365693 & 100.00 & 365693 & 100.00 & 0.00 & \\
\hline \multirow{7}{*}{ (4) } & 1: arable land & 152048 & 34.40 & 149145 & 33.74 & -2903.07 & -1.91 \\
\hline & 2: woodland & 60610 & 13.71 & 63893 & 14.45 & 3283.34 & 5.42 \\
\hline & 3: grassland & 176258 & 39.87 & 172955 & 39.13 & -3302.33 & -1.87 \\
\hline & 4: Water & 8145 & 1.84 & 8249 & 1.87 & 104.24 & 1.28 \\
\hline & 5: urban land & 10975 & 2.48 & 13936 & 3.15 & 2961.19 & 26.98 \\
\hline & 6: unused land & 34013 & 7.69 & 33870 & 7.66 & -143.37 & -0.42 \\
\hline & SUM & 442048 & 100.00 & 442048 & 100.00 & 0.00 & \\
\hline \multirow{7}{*}{ (5) } & 1: arable land & 161018 & 45.98 & 157066 & 44.85 & -3951.33 & -2.45 \\
\hline & 2: woodland & 60383 & 17.24 & 64629 & 18.45 & 4245.78 & 7.03 \\
\hline & 3: grassland & 98911 & 28.24 & 93267 & 26.63 & -5644.73 & -5.71 \\
\hline & 4: water & 7479 & 2.14 & 8177 & 2.33 & 697.39 & 9.32 \\
\hline & 5: urban land & 15471 & 4.42 & 20370 & 5.82 & 4898.15 & 31.66 \\
\hline & 6: unused land & 6945 & 1.98 & 6700 & 1.91 & -245.26 & -3.53 \\
\hline & SUM & 350208 & 100.00 & 350208 & 100.00 & 0.00 & \\
\hline
\end{tabular}

average number of rainless days gradually decreases from 352 days to 325 days. The mean WYC values of the five types were linearly correlated with average precipitation, rainstorm days, rainless days, and NDVI, yielding $R^{2}$ values of 0.98 , $0.91,0.96$, and 0.73 , respectively (Figure 25). Among these factors, the WYC is negatively correlated with the number of rainless days and positively correlated with the other factors; however, the correlation with vegetation coverage was poor. Table 2 lists the LUC in various regions. From the first type to the fifth type, the area of arable land gradually increases from $18.14 \%$ to $72.49 \%$, while the proportion of grassland gradually decreases from $54.56 \%$ to $3.92 \%$. The area of woodland increases gradually from the first type to the third type but gradually decreased in the fourth and fifth types. In the five region types, the sum of the proportions of arable land, woodland, and grassland are $75.14 \%, 89.09 \%$, $91.66 \%, 86.12 \%$, and $83.91 \%$, respectively. In terms of ET, the different LUC types are ordered as follows: water area $>$ arable land $>$ woodland $>$ grassland $>$ urban land. This pattern, in combination with the change in vegetation coverage, suggests that although the vegetation coverage from the first type to the fifth type gradually increases, the area with the highest ET should be the third region type. Therefore, in the correlation maps between NDVI and WYC, the vegetation cover of the 
TABLE 2: Area of different LUC types in various type regions.

\begin{tabular}{|c|c|c|c|}
\hline Classification & Land use type & Average area $\left(\mathrm{km}^{2}\right)$ & Average proportion (\%) \\
\hline \multirow{7}{*}{ (1) } & 1: arable land & 27337 & 18.14 \\
\hline & 2: woodland & 3686 & 2.45 \\
\hline & 3: grassland & 82239 & 54.56 \\
\hline & 4: water & 3592 & 2.38 \\
\hline & 5: urban land & 3253 & 2.16 \\
\hline & 6: unused land & 30630 & 20.32 \\
\hline & SUM & 150736 & 100.00 \\
\hline \multirow{7}{*}{ (2) } & 1: arable land & 103399 & 27.17 \\
\hline & 2: woodland & 48223 & 12.67 \\
\hline & 3: grassland & 187406 & 49.25 \\
\hline & 4: water & 6310 & 1.66 \\
\hline & 5: urban land & 5413 & 1.42 \\
\hline & 6: unused land & 29801 & 7.83 \\
\hline & SUM & 380552 & 100.00 \\
\hline \multirow{7}{*}{ (3) } & 1: arable land & 199367 & 44.03 \\
\hline & 2: woodland & 88983 & 19.65 \\
\hline & 3: grassland & 126654 & 27.97 \\
\hline & 4: water & 8097 & 1.79 \\
\hline & 5: urban land & 23947 & 5.29 \\
\hline & 6: unused land & 5725 & 1.26 \\
\hline & SUM & 452773 & 100.00 \\
\hline \multirow{7}{*}{ (4) } & 1: arable land & 132504 & 54.93 \\
\hline & 2: woodland & 32208 & 13.35 \\
\hline & 3: grassland & 43039 & 17.84 \\
\hline & 4: water & 5924 & 2.46 \\
\hline & 5: urban land & 22106 & 9.16 \\
\hline & 6: unused land & 5453 & 2.26 \\
\hline & SUM & 241234 & 100.00 \\
\hline \multirow{7}{*}{ (5) } & 1: arable land & 139954 & 72.49 \\
\hline & 2: woodland & 14465 & 7.49 \\
\hline & 3: grassland & 7570 & 3.92 \\
\hline & 4: water & 10558 & 5.47 \\
\hline & 5: urban land & 20401 & 10.57 \\
\hline & 6: unused land & 111 & 0.06 \\
\hline & SUM & 193059 & 100.00 \\
\hline
\end{tabular}

third type is higher than that of the second type, but the WYC does not change. From the fourth type to the fifth type, the increase in vegetation coverage is small, and the amount of ET decreases. Simultaneously, the precipitation characteristics tend to increase, leading to an increase in the average WYC.

The above analysis indicates that the average WYC has the highest correlations with precipitation characteristics and that the correlations with the underlying surface conditions, such as vegetation coverage and LUC, are relatively small. The WYC is positively correlated with precipitation and rainstorm days, negatively correlated with rainless days, and positively correlated with vegetation coverage, but the correlation coefficient is greatly influenced by the precipitation characteristics and the LUC types.

\section{Discussion and Conclusions}

The selection of an interpolation method is related to the accuracy of the data analysis. In this paper, we compared several commonly used spatial interpolation methods to interpolate the spatial distribution of precipitation and WYC. These methods included the IDW method, Kriging method, natural neighbour method, spline interpolation method, topo to raster method, and trend interpolation method. The IDW method is a commonly used and simple method of spatial interpolation. It takes the distance between an interpolation point and a sample point as the weighted average, and sample points closer to the interpolation point are given more weight as the weight is inversely proportional to the distance [41]. This method has been used by many scholars 


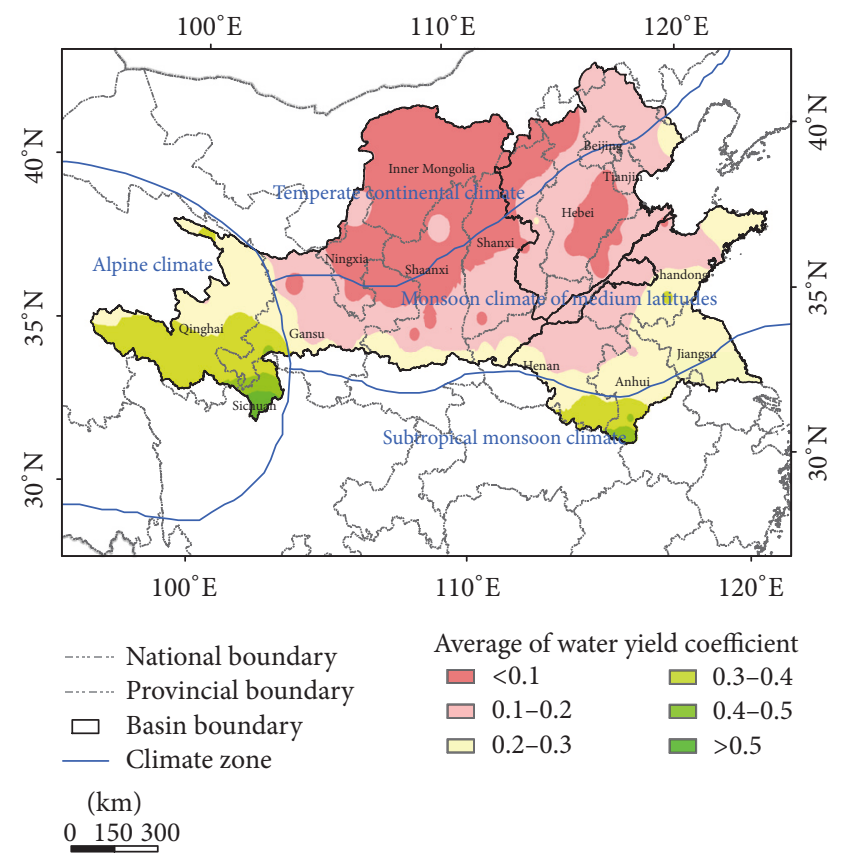

FIGURE 15: Multiyear average WYC spatial distribution from 1961 to 2011.

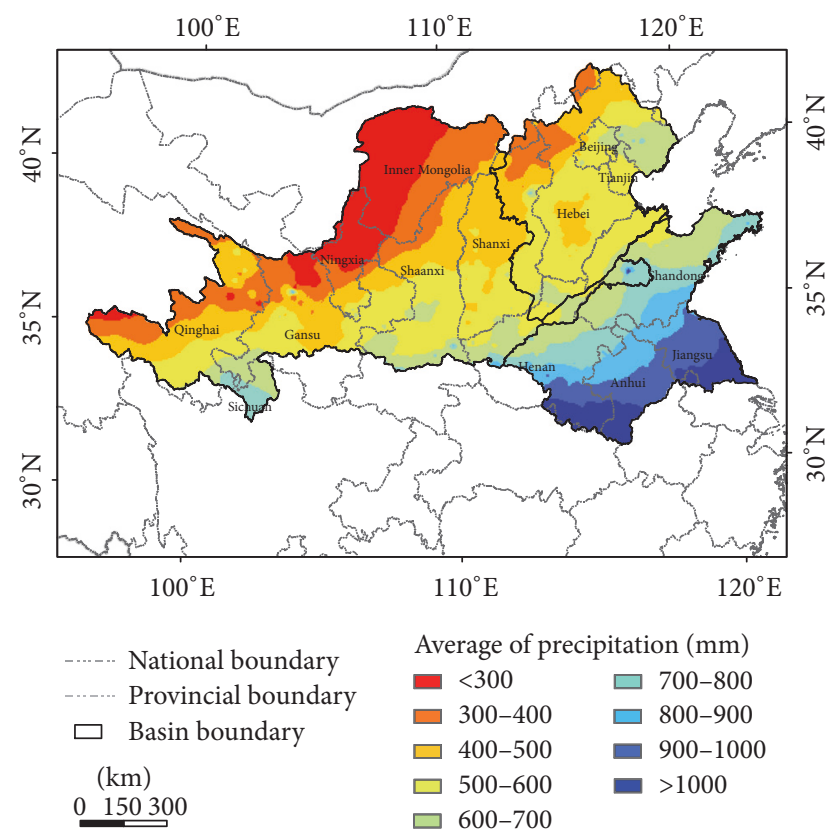

FIGURE 16: The spatial distribution of multiyear average precipitation values from 1961 to 2011.

to interpolate precipitation. Gemmer et al. used the IDW method to interpolate the monthly precipitation data of 160 stations in China from 1951 to 2002 and analysed the trends [42]. Chen and Liu used the IDW method to estimate rainfall distribution in central Taiwan [43], and Modallaldoust used it to interpolate the mean precipitation in the Jam and Riz basins in Iran, obtaining the highest degree of fitting by changing different parameters to facilitate data entry into the

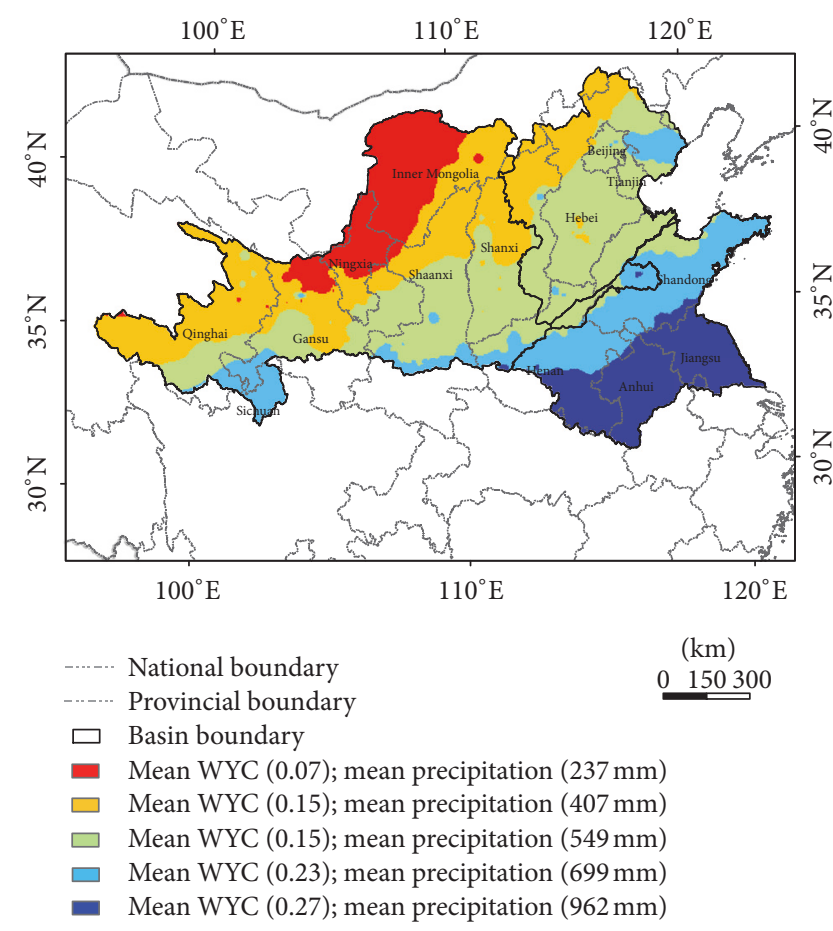

FIgURE 17: Cluster distribution.

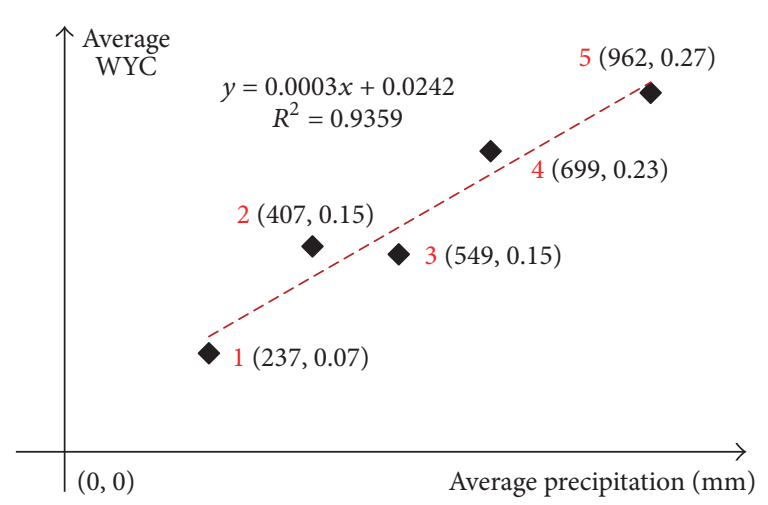

FIGURE 18: The coupled relationship between average WYC and precipitation from 1961 to 2011.

hydrological model [44]. The Kriging method assumes that the distance or direction between sampling points reflects and accounts for the spatial dependence of the surface change by fitting the mathematical function to a specified number of points or all points within a specified radius to determine each output value of the position. Nusret and Dug compared the IDW and Kriging methods when drawing annual precipitation maps of Bosnia and Herzegovina and concluded that the Kriging method is more accurate and suitable for that area. Additionally, the interpolation results of the IDW method are not very good in mountainous area [45]. The principle of the natural neighbour method involves first constructing Voronoi polygons. When the unknown points are interpolated, a Voronoi polygon is also constructed to produce numerous intersections with the original polygons; then, the value of the point is determined according to 


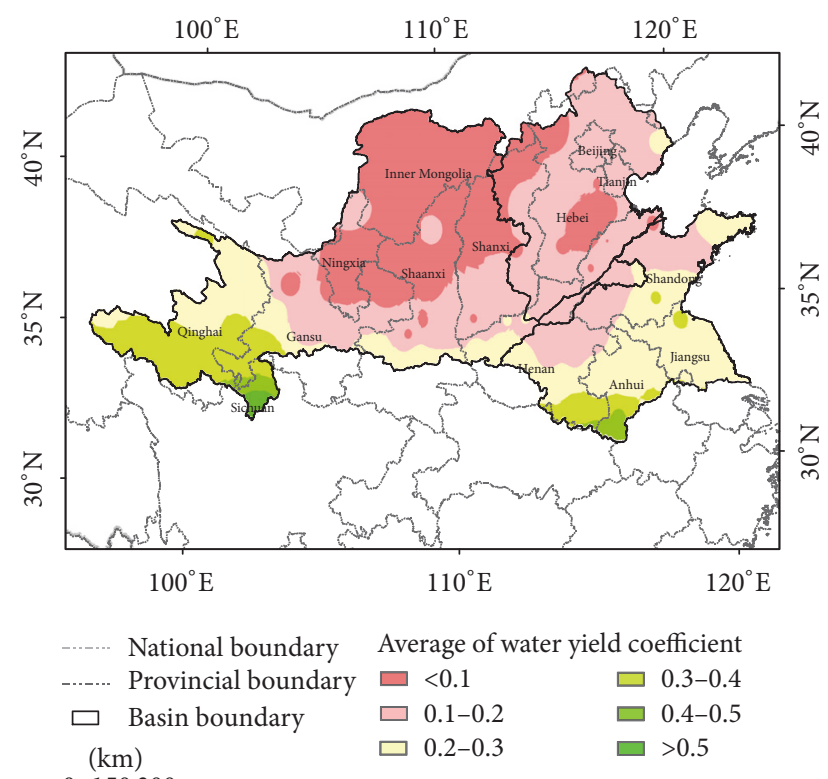

$0 \quad 150300$

FIGURE 19: The spatial distribution of multiyear average WYC from 1982 to 2011.

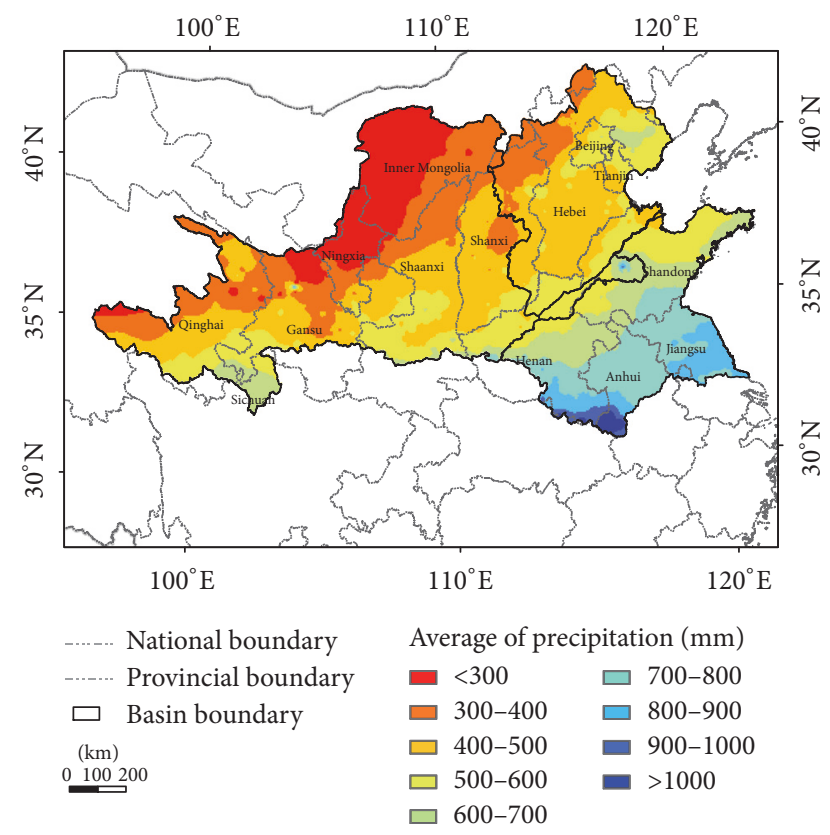

FIgURE 20: The spatial distribution of multiyear average precipitation from 1982 to 2011.

the proportion of each area [46]. Spline interpolation is a mathematical function interpolation using two-dimensional minimum curvature to generate a smooth surface just past the input point. This method is best suited to model gently varying surfaces, such as elevation, groundwater level, or contamination [47]. The topo to raster method is specifically designed to create digital elevation models (DEMs) that match the true surface. The trend is the actual distribution of a spatial trend surface that fits a geographic feature. The last

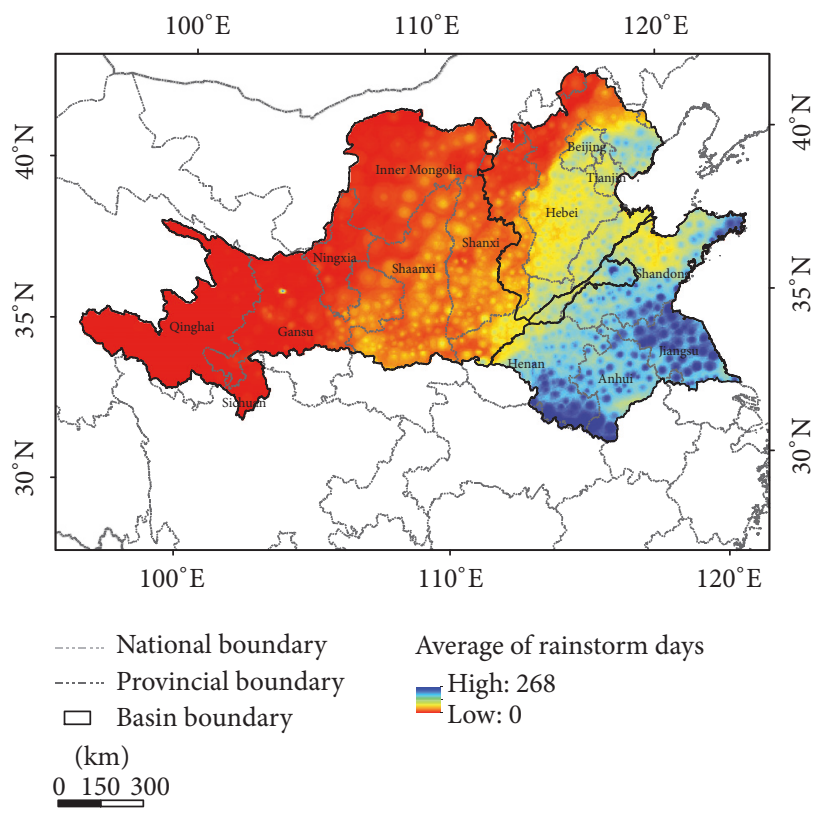

FIGURE 21: The spatial distribution of multiyear average rainstorm days from 1982 to 2011.

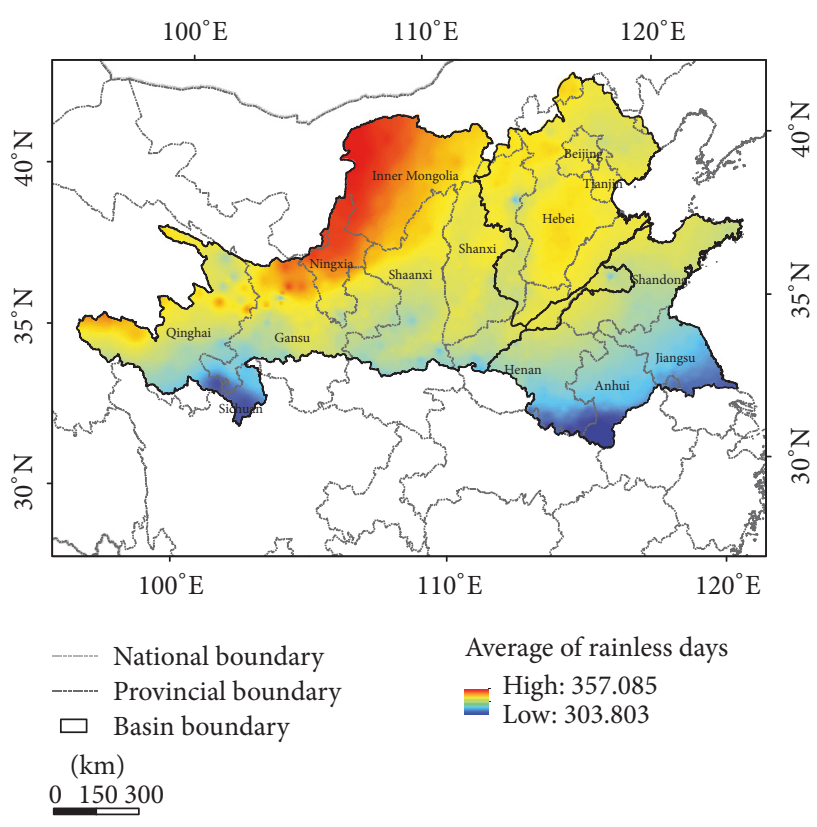

FIGURE 22: The spatial distribution of multiyear average rainless days from 1982 to 2011.

two methods are less commonly used for hydrographic data interpolation.

Many scholars have compared different spatial interpolation methods according to their different research goals. The results show that the strengths and weaknesses of each method are different under different conditions [48-50]. This paper mainly studies the changes in the WYC by using the average WYC of each city for spatial interpolation to obtain the spatial distribution. Therefore, we randomly selected 12 


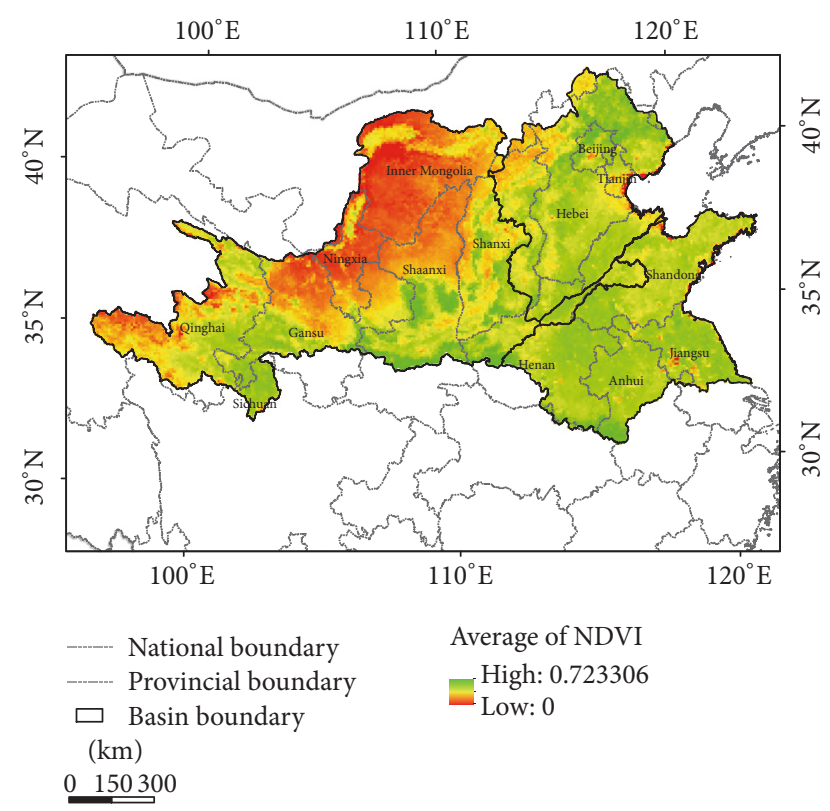

FIGURE 23: The spatial distribution of multiyear average NDVI from 1982 to 2011.

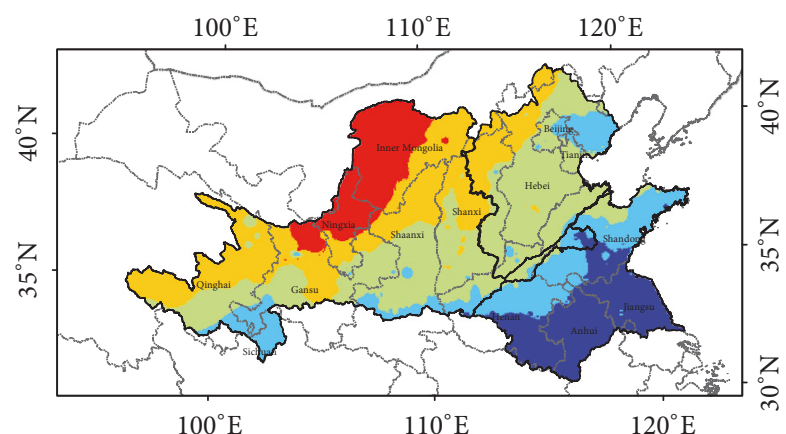

National boundary
Provincial boundary
Basin boundary
WYC (0.08); precipitation (222 mm); NDVI (0.20); rainstorm
days (4); rainless days (352)
WYC (0.15); precipitation (375 mm); NDVI (0.33); rainstorm
days (9); rainless days (341)
$\square$ WYC (0.15); precipitation (487 mm); NDVI (0.48); rainstorm
days (35); rainless days (337)
WYC (0.21); precipitation (601 mm); NDVI (0.52); rainstorm
days (78); rainless days (334)
WYC (0.28); precipitation (784 mm); NDVI (0.53); rainstorm
days (135); rainless days (325)

FIGURE 24: Cluster distribution.

cities evenly distributed throughout the basin (Figure 26). The results obtained from the six interpolation methods in ArcGIS in 1961 were compared with the average WYC for each city, and the results are shown in Figure 27 and Table 3. As shown in Figure 27, the gradient of the results is not smooth enough when calculated by the Kriging method, and the interpolated results of the trend method are quite anomalous. The spline and topo to raster methods yield negative interpolated values. As shown in Table 3, for the 12 cities, the smallest error between the interpolated results and the average values was produced by the IDW method in 6 cities, the spline method in 4 cities, and the natural neighbour and topo to raster methods in 1 city each. In Anyang City, for the six methods, the minimum error is $20 \%$, the rest are below $10 \%$, and the minimum is $0.2 \%$. The trend method has the highest error in terms of interpolation results, the Kriging method produced the largest error variation, and the other four methods have relatively small errors. According to the analysis of the interpolation map and the error comparison, the IDW method has a smaller number of errors than the spline method, which has a negative value in the graph. Therefore, the IDW method is selected as the interpolation method in this paper.

Based on the above analysis, we have come to the following conclusions.

(1) The average annual WYC of the Huang-Huai-Hai River Basin is between 0.03 and 0.58 , with an average of 0.17 . This average is smaller than the national average WYC of 0.4 . The smallest value appears in the middle of the HuangHuai-Hai River Basin, and the largest value appears in the south. The study area can be roughly divided into six types in terms of the spatial distribution of values, that is, $<0.1$, $0.1-0.2,0.2-0.3,0.3-0.4,0.4-0.5$, and $>0.5$, which account for $29.7 \%, 38.1 \%, 22.1 \%, 8.8 \%, 1.0 \%$, and $0.4 \%$ of the area, respectively. The average annual precipitation in the basin ranges from 119 to $1103 \mathrm{~mm}$, increasing from the interior to the eastern coast. The average annual precipitation is less than $300 \mathrm{~mm}$ in the Hetao Plain in the northwestern Huang-HuaiHai River Basin but is greater than $800 \mathrm{~mm}$ in North China. The multiyear average NDVI value is between 0 and 0.72 , and although the quality of vegetation cover in the central and northern parts of the Yellow River Basin has improved, it remains lower than in other areas. The distribution of rainless days gradually decreases from the interior to the southeastern coast. The spatial distribution of rainstorm days gradually increases from west to east (from the Yellow River to the Hai River to the Huai River) in a step-like pattern.

(2) For the time period of 1961 to 2011, the WYC in the Huang-Huai-Hai River Basin varied slightly, and the rates of change varied from $-0.05 / 10 \mathrm{a}$ to $0.04 / 10 \mathrm{a}$. Generally, the western region showed a negative trend, and the eastern region showed a positive trend. In terms of rates of change, precipitation and rainstorm days were positively correlated with the WYC, whereas rainless days were negatively correlated with the WYC. Although NDVI was positively correlated with the WYC, a slower change in the NDVI resulted in a faster change in the WYC. Changes in the LUC type can change the ET, thereby affecting the trend of WYC.

(3) As shown in the spatial pattern, the average WYC in the Huang-Huai-Hai River Basin gradually increases from the northern part of the Yellow River Basin (WYC < 0.1) to the surrounding areas. The multiyear average annual WYC in the southern part of Yellow River Basin (Sichuan Province) is greater than 0.5. After clustering analysis and plotting the WYC with various factors, the $R^{2}$ values of precipitation, rainstorm days, rainless days, and NDVI were found to 


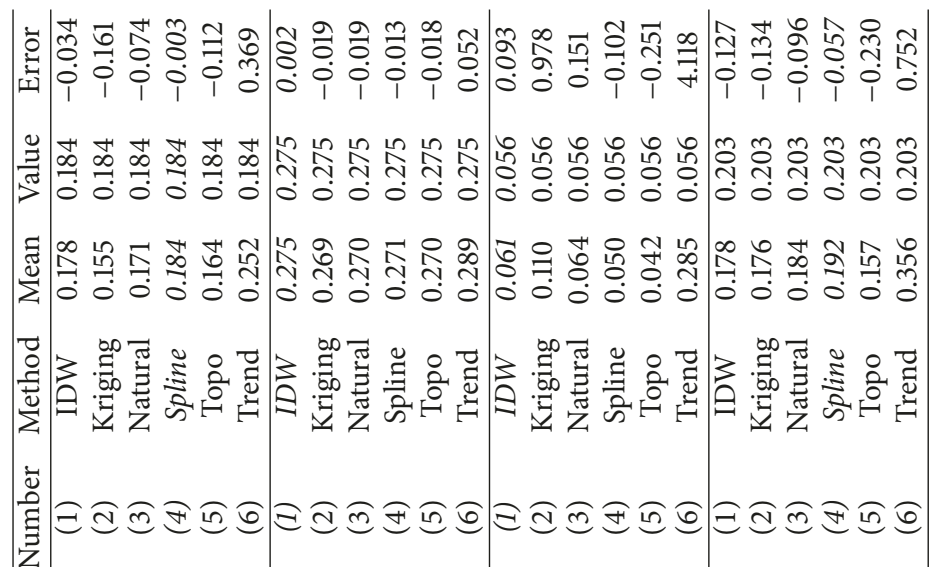



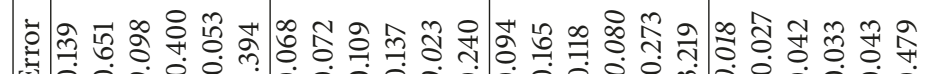
离

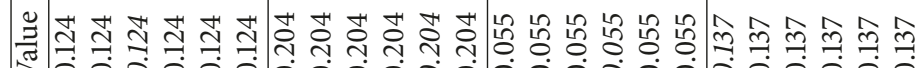

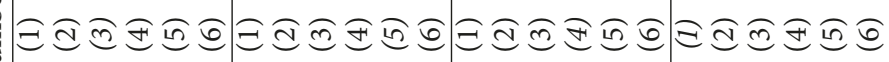

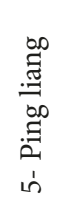

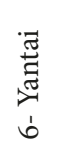

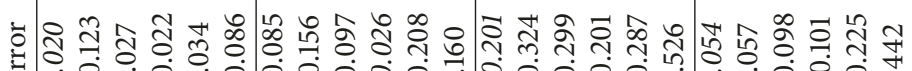

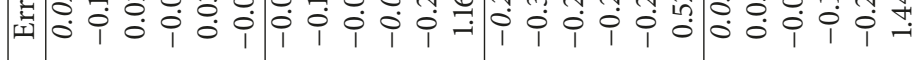
至角

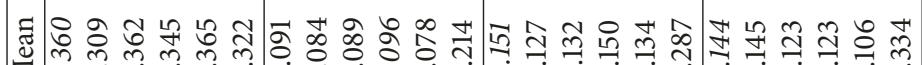

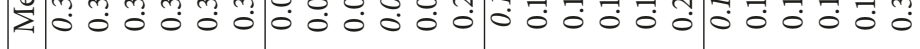

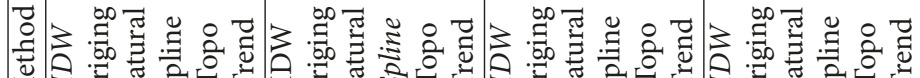

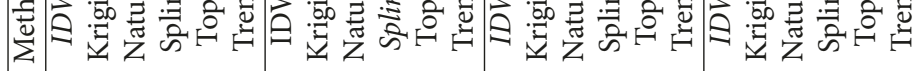
矛 z 氙 跑

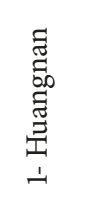

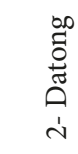




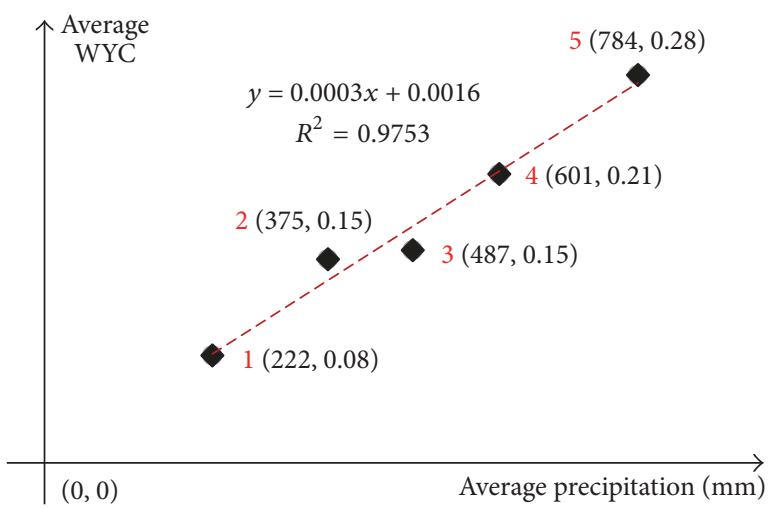

(a)

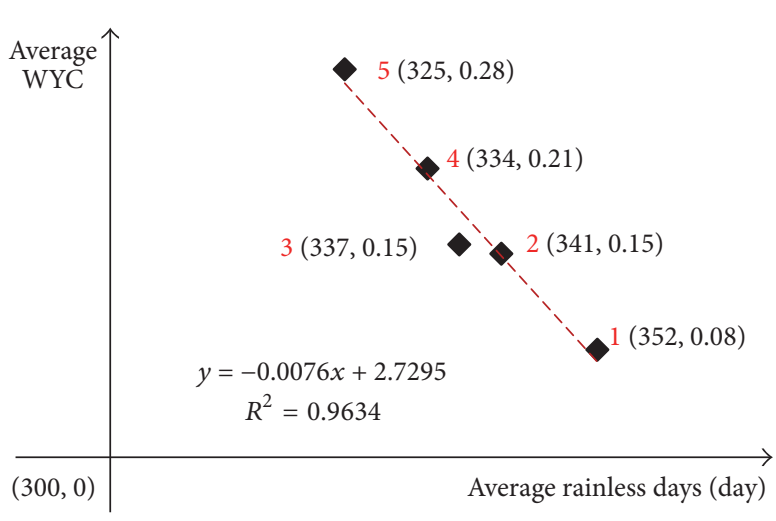

(c)

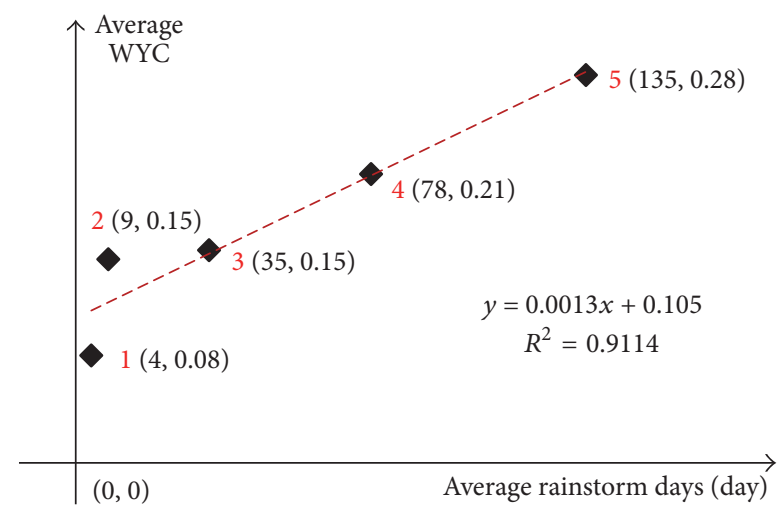

(b)

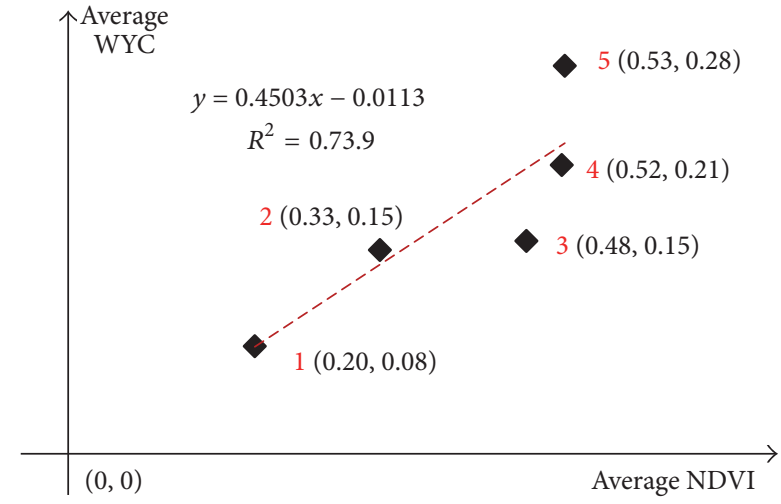

(d)

Figure 25: The coupled relationships between average WYC and four factors from 1982 to 2011.

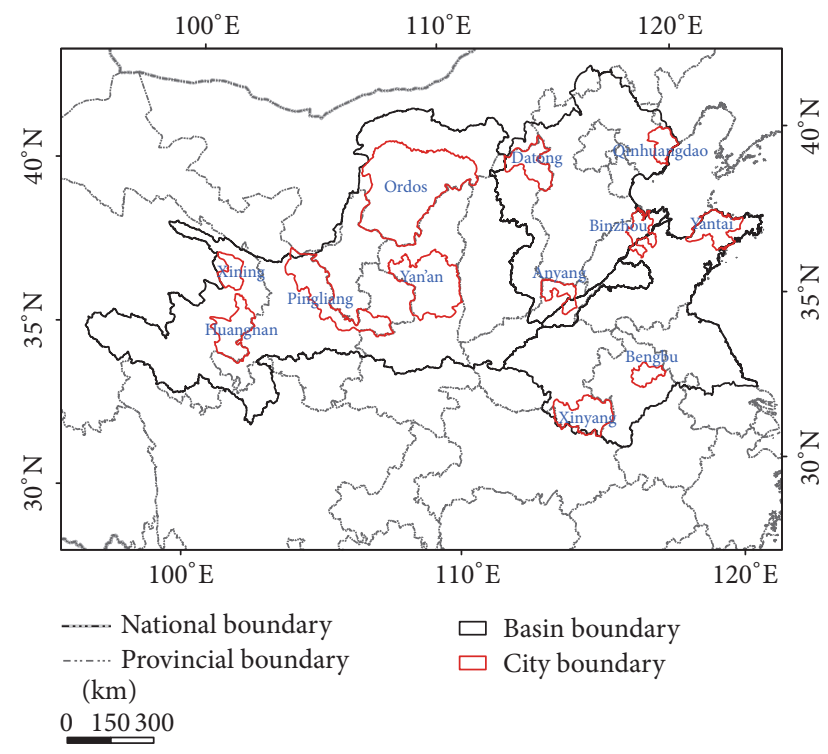

FIGURE 26: Spatial distribution of the selected twelve cities.

be $0.98,0.91,0.96$, and 0.73 , respectively. The correlation between the WYC and the precipitation characteristics is the largest, and the correlation between the WYC and the underlying surface conditions is relatively small. The WYC is positively correlated with precipitation and rainstorm days, negatively correlated with rainless days, and positively correlated with vegetation coverage, but the correlation coefficients are greatly influenced by the precipitation characteristics and the LUC types.

(4) In this paper, we analysed the temporal and spatial variation characteristics of the WYC in the Huang-HuaiHai River Basin, mainly considering two types of factors, precipitation characteristics (precipitation, the number of rainstorm days, and the number of rainless days), and the underlying surface conditions (NDVI and LUC). For future research, we will consider adding more factors, such as temperature and ET, and subdividing the study area to make the results more reliable.

\section{Conflicts of Interest}

The authors declare that there are no conflicts of interest regarding the publication of this paper.

\section{Acknowledgments}

This work was supported by the National Key Research and Development Project (no. 2016YFA0601503, no. 2017YFA0605004) and the Representative Achievements and Cultivation Project of the State Key Laboratory of the 

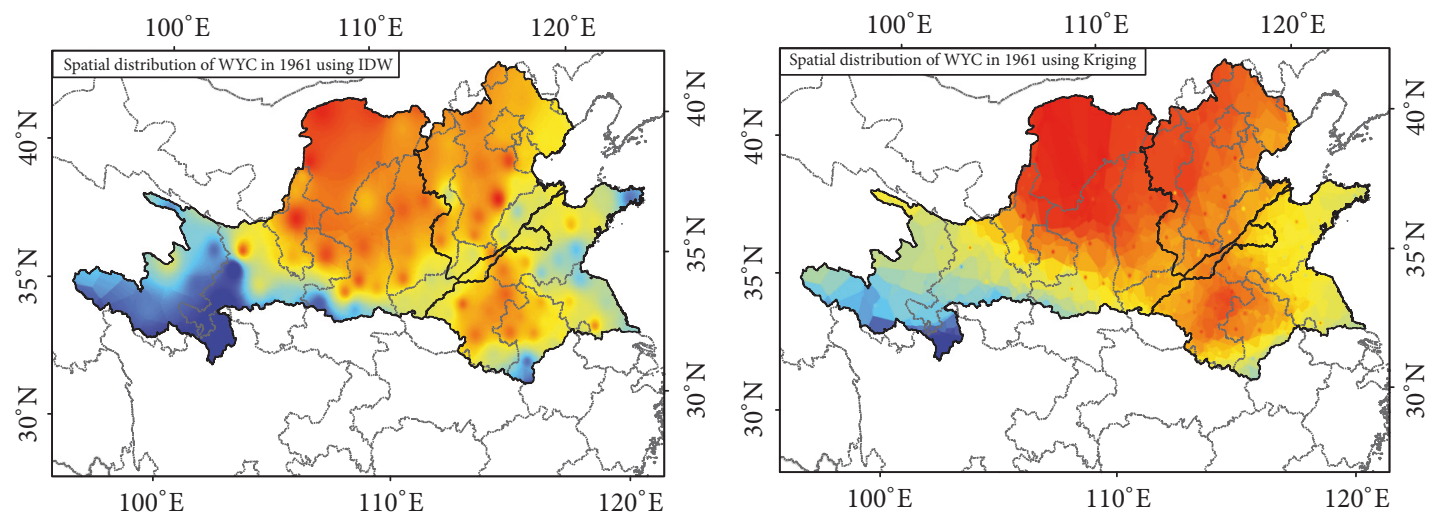

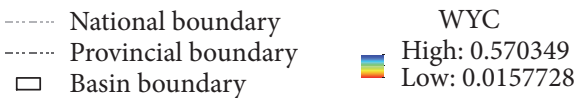
$(\mathrm{km})$

$0 \quad 150300$

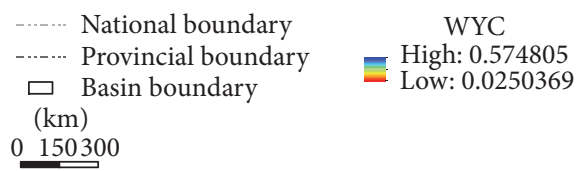

(a)

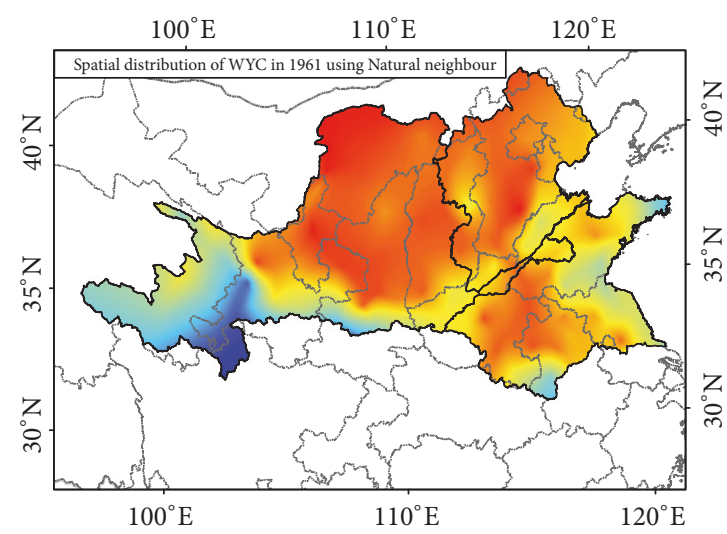

National boundary WYC

…… High: 0.578466

$\square \quad$ Basin boundary

$(\mathrm{km})$

$0 \quad 150300$

(c)

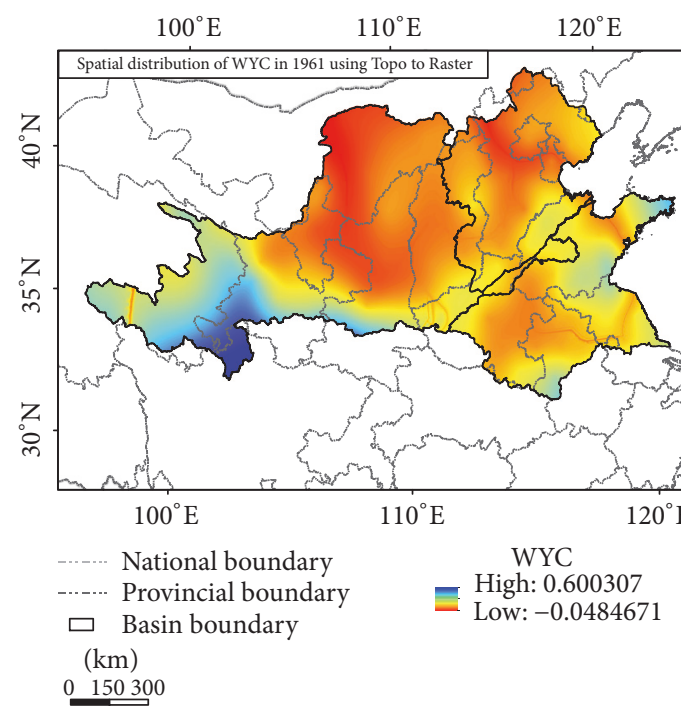

(e) (b)

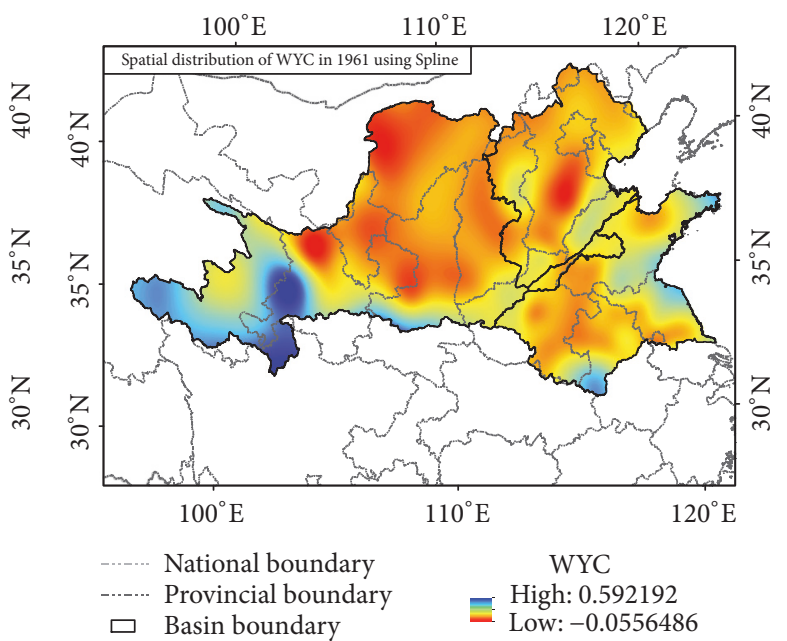

$(\mathrm{km})$

$0 \quad 150300$

(d)

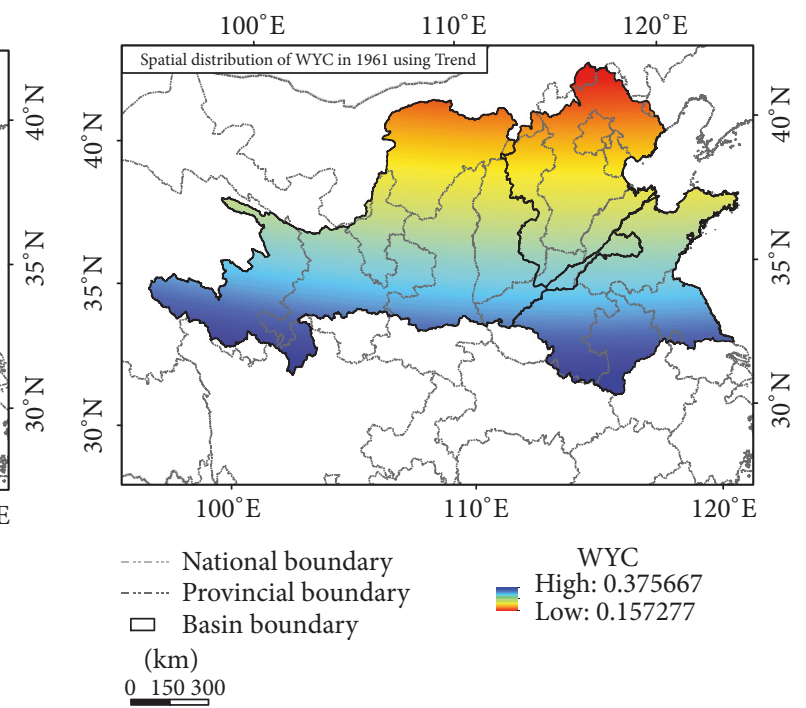

(f)

FIGURE 27: Interpolation results for six different methods. 
Simulation and Regulation of the Water Cycle in the River Basin (no. 2016CG02); and Chinese National Natural Science Foundation (no. 51409267).

\section{References}

[1] G. Heuvelmans, B. Muys, and J. Feyen, "Extending the life cycle methodology to cover impacts of land use systems on the water balance," The International Journal of Life Cycle Assessment, vol. 10, no. 2, pp. 113-119, 2005.

[2] W. H. Schlesinger and S. Jasechko, "Transpiration in the global water cycle," Agricultural and Forest Meteorology, vol. 189-190, pp. 115-117, 2014.

[3] F. Wu, J. Zhan, H. Su, H. Yan, and E. Ma, "Scenario-Based Impact Assessment of Land Use/Cover and Climate Changes on Watershed Hydrology in Heihe River Basin of Northwest China," Advances in Meteorology, vol. 2015, Article ID 410198, 11 pages, 2015.

[4] B. M. Albert, "Past vegetation influence on the hydrological cycle in the Chihuahuan Desert, North Mexico as indicated by data of four pollen sites," Quaternary International, vol. 374, pp. 168-181, 2015.

[5] C. Gyamfi, J. M. Ndambuki, and R. W. Salim, "Hydrological responses to land use/cover changes in the Olifants Basin, South Africa," Water (Switzerland), vol. 8, no. 12, article no. 588, 2016.

[6] S. Pan, D. Liu, Z. Wang et al., "Runoff responses to climate and land use/cover changes under future scenarios," Water, vol. 9, no. 7, article 475, 2017.

[7] R. Seager, N. Naik, and G. A. Vecchi, "Thermodynamic and dynamic mechanisms for large-scale changes in the hydrological cycle in response to global warming," Journal of Climate, vol. 23, no. 17, pp. 4651-4668, 2010.

[8] J. Liu, B. Wang, M. A. Cane, S.-Y. Yim, and J.-Y. Lee, “Divergent global precipitation changes induced by natural versus anthropogenic forcing," Nature, vol. 493, no. 7434, pp. 656-659, 2013.

[9] K. E. Trenberth, A. Dai, G. Van Der Schrier et al., "Global warming and changes in drought," Nature Climate Change, vol. 4, no. 1, pp. 17-22, 2014.

[10] M. G. Donat, A. L. Lowry, L. V. Alexander, P. A. O'Gorman, and N. Maher, "More extreme precipitation in the world's dry and wet regions," Nature Climate Change, vol. 6, no. 5, pp. 508-513, 2016.

[11] W. W. Shao, H. Huang, J. H. Wang, and L. Cao, "Analysis on the development state and problems of the water resources in the basins of yellow river, huaihe river and haihe river," Journal of China Institute of Water Resources Hydropower Research, vol. 10, pp. 301-309, 2012 (Chinese).

[12] G. Q. Wang and J. Y. Zhang, "Variation of water resources in the Huang-huai-hai areas and adaptive strategies to climate change," Quaternary International, vol. 380-381, pp. 180-186, 2015.

[13] D.-D. Zhang, D.-H. Yan, Y.-C. Wang, F. Lu, and D. Wu, "Changes in extreme precipitation in the Huang-Huai-Hai River basin of China during 1960-2010," Theoretical and Applied Climatology, vol. 120, no. 1-2, pp. 195-209, 2015.

[14] D. H. Yan, D. Wu, R. Huang, L. N. Wang, and G. Y. Yang, "Drought evolution characteristics and precipitation intensity changes during alternating dry-wet changes in the HuangHuai-Hai River basin," Hydrology and Earth System Sciences, vol. 17, no. 7, pp. 2859-2871, 2013.
[15] J. Yin, D. Yan, Z. Yang, Z. Yuan, Y. Yuan, and C. Zhang, "Projection of extreme precipitation in the context of climate change in Huang-Huai-Hai region, China," Journal of Earth System Science, vol. 125, no. 2, pp. 417-429, 2016.

[16] Z. Yang, Z. Yuan, D. Yan, Y. Yu, and B. Weng, "Study of spatial and temporal distribution and multiple characteristics of drought and flood in Huang-Huai-Hai River basin," Advances in Water Science, vol. 24, no. 5, pp. 617-625, 2013 (Chinese).

[17] Z. Yuan, D.-H. Yan, Z.-Y. Yang, J. Yin, and Y. Yuan, “Temporal and spatial variability of drought in Huang-Huai-Hai River Basin, China," Theoretical and Applied Climatology, vol. 122, no. 3-4, pp. 755-769, 2015.

[18] L. S. Hao, J. Z. Min, and K. Y. Liu, "Impact of climate change on hebei water resource," Journal of Hebei Normal University, vol. 34, pp. 491-496, 2010 (Chinese).

[19] Y. H. Sun, L. Feng, J. X. Wu, and H. L. Li, "Study of future water resources quantity forecast method for water deficient area," Water Resources Hydropower of Northeast China, vol. 29, pp. 3537, 2011 (Chinese).

[20] G. Gao and C. Y. Huang, "Study of water resources annual assessment and its application in China," Quarterly of Applied Mathematics, vol. 16, pp. 105-110, 2005 (Chinese).

[21] D. Gerten, S. Schaphoff, U. Haberlandt, W. Lucht, and S. Sitch, "Terrestrial vegetation and water balance - Hydrological evaluation of a dynamic global vegetation model," Journal of Hydrology, vol. 286, no. 1-4, pp. 249-270, 2004.

[22] S. M. Sterling, A. Ducharne, and J. Polcher, "The impact of global land-cover change on the terrestrial water cycle," Nature Climate Change, vol. 3, no. 4, pp. 385-390, 2013.

[23] V. Mishra, K. A. Cherkauer, and D. Niyogi, "A regional scale assessment of land use/land cover and climatic changes on water and energy cycle in the upper Midwest United States," International Journal of Climatology, vol. 30, no. 13, pp. 20252044, 2010.

[24] T. E. Twine, C. J. Kucharik, and J. A. Foley, "Effects of land cover change on the energy and water balance of the Mississippi River basin," Journal of Hydrometeorology, vol. 5, no. 4, pp. 640-655, 2004.

[25] M. Liu, H. Tian, G. Chen, W. Ren, C. Zhang, and J. Liu, "Effects of land-use and land-cover change on evapotranspiration and water yield in China during 1900-2000," JAWRA Journal of the American Water Resources Association, vol. 44, no. 5, pp. 1193 1207, 2008.

[26] T. Oki and S. Kanae, "Global hydrological cycles and world water resources," Science, vol. 313, no. 5790, pp. 1068-1072, 2006.

[27] B. R. Scanlon, R. C. Reedy, D. A. Stonestrom, D. E. Prudic, and K. F. Dennehy, "Impact of land use and land cover change on groundwater recharge and quality in the southwestern US," GCB Bioenergy, vol. 11, no. 10, pp. 1577-1593, 2005.

[28] S. Piao, P. Friedlingstein, P. Ciais, N. De Noblet-Ducoudré, D. Labat, and S. Zaehle, "Changes in climate and land use have a larger direct impact than rising $\mathrm{CO} 2$ on global river runoff trends," Proceedings of the National Acadamy of Sciences of the United States of America, vol. 104, no. 39, pp. 15242-15247, 2007.

[29] D. Gerten, S. Rost, W. von Bloh, and W. Lucht, "Causes of change in 20th century global river discharge," Geophysical Research Letters, vol. 35, no. 20, 2008.

[30] M. Jung, M. Reichstein, P. Ciais et al., "Recent decline in the global land evapotranspiration trend due to limited moisture supply," Nature, vol. 467, no. 7318, pp. 951-954, 2010. 
[31] C. J. Vörösmarty and D. Sahagian, "Anthropogenic disturbance of the terrestrial water cycle," Bioscience, vol. 50, no. 9, pp. 753$765,2000$.

[32] M. Scheffer, M. Holmgren, V. Brovkin, and M. Claussen, "Synergy between small- And large-scale feedbacks of vegetation on the water cycle," Global Change Biology, vol. 11, no. 7, pp. 10031012, 2005.

[33] F. X. Shen, L. H. Geng, F. X. Qin, and P. B. Xu, "Analysis of water saving in received area in huanghe-huaihe-haihe watersheds and eastern and middle lines of water transferring project from south to north, China," Advances in Water Science, vol. 13, pp. 768-774, 2002 (Chinese).

[34] J. Guo and G.-Y. Ren, "Recent change of pan evaporation and possible climate factors over the Huang-Huai-Hai watershed, China," Shuikexue Jinzhan/Advances in Water Science, vol. 16, no. 5, pp. 666-672, 2005.

[35] M. Garcia, C. D. Peters-Lidard, and D. C. Goodrich, "Spatial interpolation of precipitation in a dense gauge network for monsoon storm events in the southwestern United States," Water Resources Research, vol. 44, no. 5, pp. 782-781, 2008.

[36] R. Fensholt and S. R. Proud, "Evaluation of Earth Observation based global long term vegetation trends - Comparing GIMMS and MODIS global NDVI time series," Remote Sensing of Environment, vol. 119, pp. 131-147, 2012.

[37] L. Cheng, Z. X. Xu, R. Luo, and Y. J. Mi, "Spatial-temporal characteristics of LUCC and driving factor analysis for the wei river basin from 1980 to 2000," Research of Soil \& Water Conservation, vol. 16, pp. 1-6, 2009 (Chinese).

[38] L. Wu, S. Yang, X. Liu, Y. Luo, X. Zhou, and H. Zhao, "Response analysis of land use change to the degree of human activities in Beiluo River basin since 1976," Dili Xuebao/Acta Geographica Sinica, vol. 69, no. 1, pp. 54-63, 2014.

[39] C. Jin, B. Zhang, K. Song, Z. Wang, and G. Yang, "RS-based analysis on the effects of land use/cover change on regional evapotranspiration - a case study in Qian'an county, Jilin province," Arid Zone Research, vol. 26, no. 5, pp. 734-743, 2010 (Chinese).

[40] X. Liu, Y. C. Zhang, D. U. Chao-Yang et al., "Current land use situation and characteristics of temporal and spatial distribution of its evapotranspiration in the Ejina Delta," South-toNorth Water Transfers and Water Science \& Technology, 2015 (Chinese).

[41] A. A. Bruch, T. Utescher, and V. Mosbrugger, "Precipitation patterns in the Miocene of Central Europe and the development of continentality," Palaeogeography, Palaeoclimatology, Palaeoecology, vol. 304, no. 3-4, pp. 202-211, 2011.

[42] M. Gemmer, S. Becker, and T. Jiang, "Observed monthly precipitation trends in China 1951-2002," Theoretical and Applied Climatology, vol. 77, no. 1-2, pp. 39-45, 2004.

[43] F.-W. Chen and C.-W. Liu, "Estimation of the spatial rainfall distribution using inverse distance weighting (IDW) in the middle of Taiwan," Paddy and Water Environment, vol. 10, no. 3, pp. 209-222, 2012.

[44] S. Modallaldoust, "Evaluating optimized digital elevation precipitation model using idw method (case study: jam \& riz watershed of assaloyeh, Iran)," Desert, pp. 5-14, 2010.

[45] D. Nusret and S. Dug, "Applying the inverse distance weighting and kriging methods ofthe spatial interpolation on themapping the annual precipitationin bosnia and herzegovina," in Proceedings of the 6th International Congress on Environmental Modelling and Software, Leipgig, Germany, 2012.
[46] A. Beutel and P. K. Agarwal, "Natural neighbor interpolation based grid DEM construction using a GPU," in Proceedings of the CM Sigspatial International Symposium on Advances in Geographic Information Systems, pp. 172-181, 2010.

[47] A. Tait, R. Henderson, R. Turner, and X. Zheng, "Thin plate smoothing spline interpolation of daily rainfall for New Zealand using a climatological rainfall surface," International Journal of Climatology, vol. 26, no. 14, pp. 2097-2115, 2006.

[48] N. Hofstra, M. Haylock, M. New, P. Jones, and C. Frei, "Comparison of six methods for the interpolation of daily, European climate data," Journal of Geophysical Research: Atmospheres, vol. 113, no. 21, pp. 6089-6098, 2008.

[49] M. W. Ashiq, C. Zhao, J. Ni, and M. Akhtar, "GIS-based highresolution spatial interpolation of precipitation in mountainplain areas of Upper Pakistan for regional climate change impact studies," Theoretical and Applied Climatology, vol. 99, no. 3-4, pp. 239-253, 2010.

[50] G. S. Bhunia, P. K. Shit, and R. Maiti, “Comparison of GIS-based interpolation methods for spatial distribution of soil organic carbon (SOC)," Journal of the Saudi Society of Agricultural Sciences, 2016. 

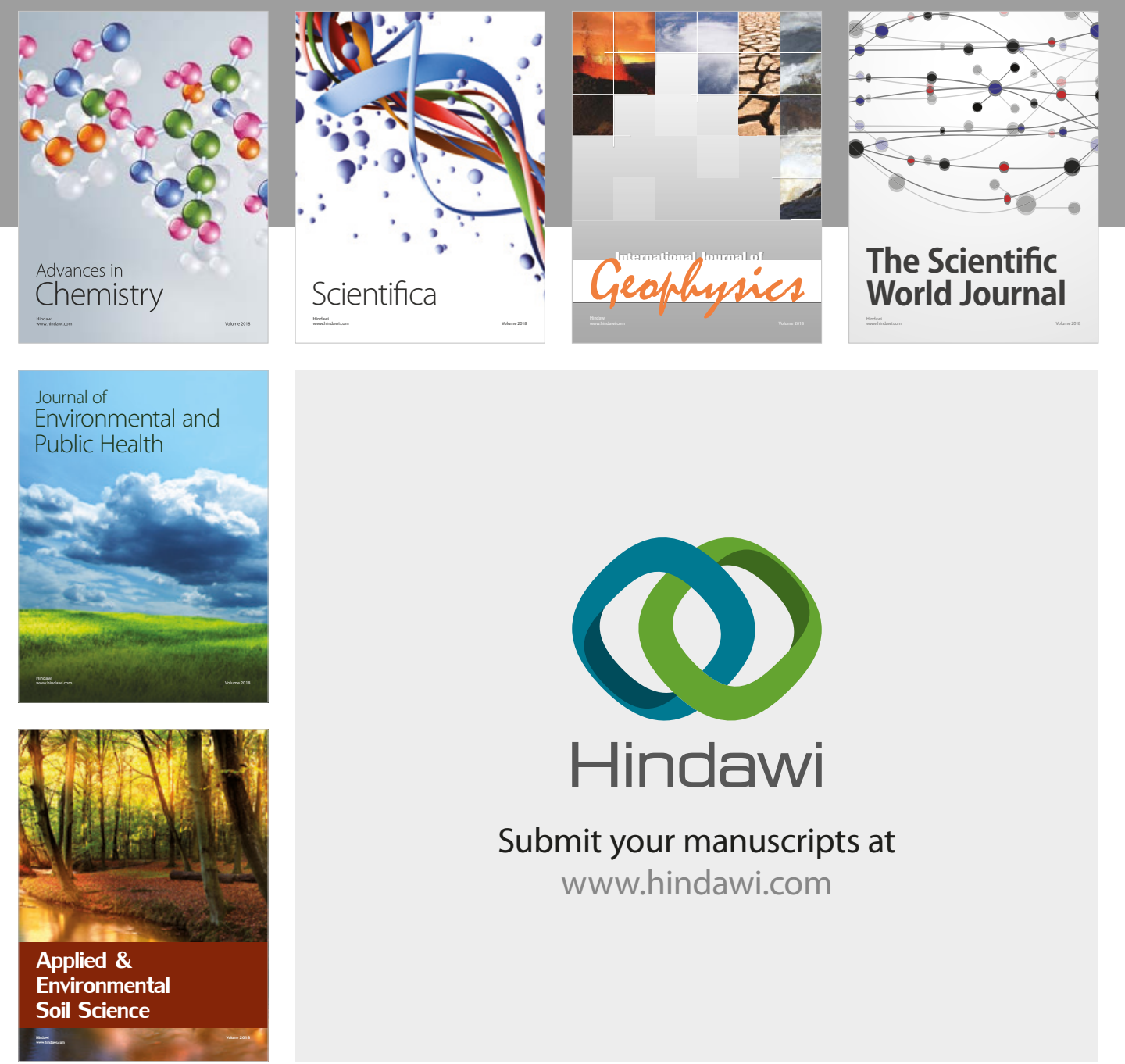

The Scientific

\section{World Journal}
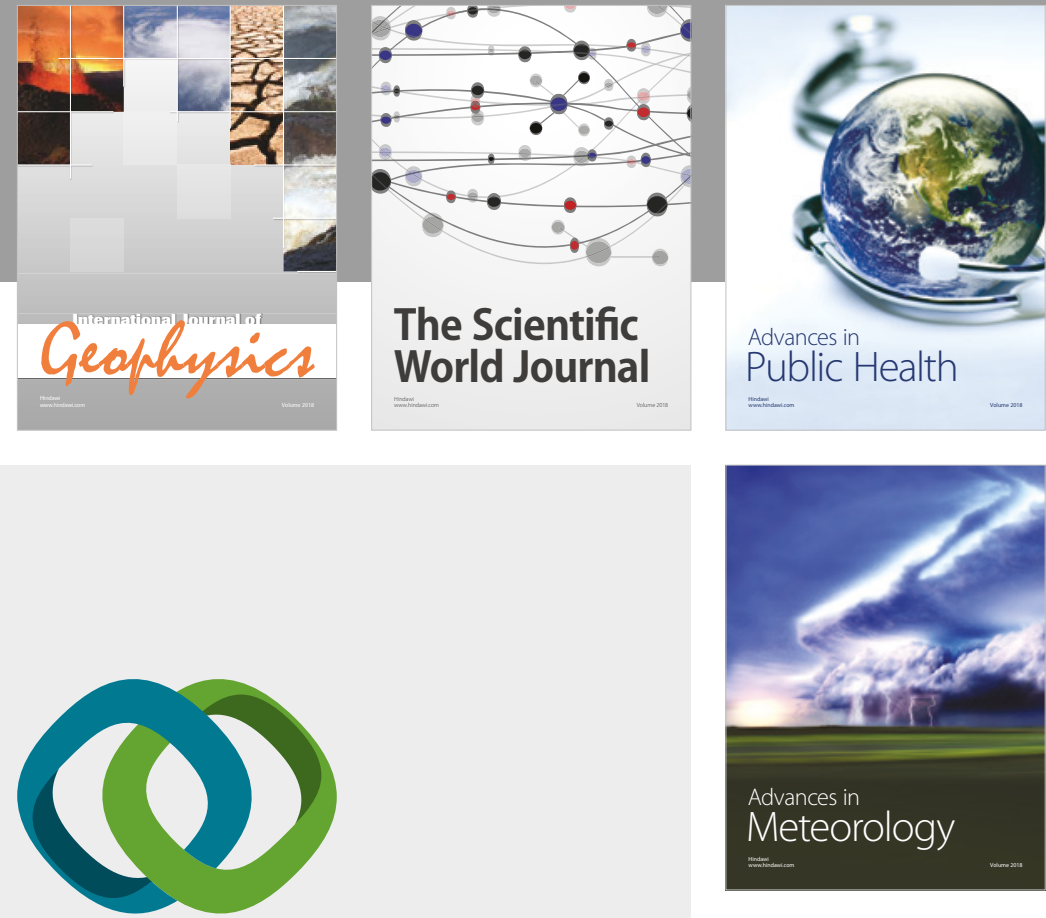

Advan

Public Health

\section{Hindawi}

Submit your manuscripts at

www.hindawi.com
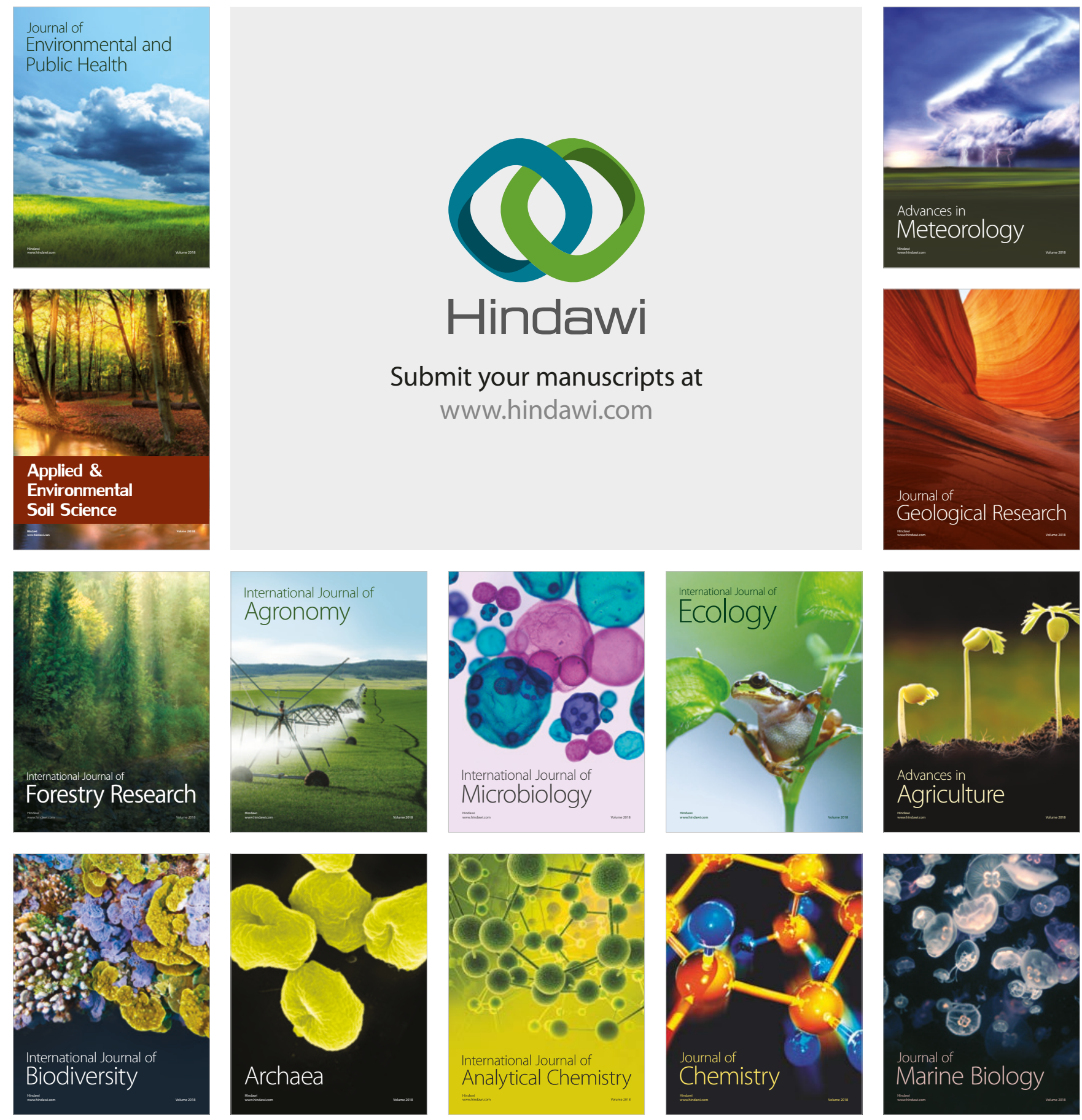